\title{
Extreme floods of Venice: characteristics, dynamics, past and future evolution (review article)
}

\author{
Piero Lionello $^{1}$, David Barriopedro ${ }^{2}$, Christian Ferrarin ${ }^{3}$, Robert J. Nicholls ${ }^{5}$, Mirko Orlic ${ }^{4}$, Fabio Raicich ${ }^{6}$, \\ Marco Reale $^{7,11}$, Georg Umgiesser ${ }^{3,10}$, Michalis Vousdoukas ${ }^{8}$, and Davide Zanchettin ${ }^{9}$ \\ ${ }^{1}$ University of Salento, DiSTeBA - Department of Biological and Environmental Sciences and Technologies, \\ via per Monteroni, 165, Lecce, Italy \\ ${ }^{2}$ Instituto de Geociencias (IGEO), CSIC-UCM, C/Doctor Severo Ochoa 7, 28040 Madrid, Spain \\ ${ }^{3}$ CNR - National Research Council of Italy, ISMAR - Marine Sciences Institute, Castello 2737/F, 30122 Venice, Italy \\ ${ }^{4}$ Department of Geophysics, Faculty of Science, University of Zagreb, Zagreb, Croatia \\ ${ }^{5}$ Tyndall Centre for Climate Change Research, University of East Anglia, Norwich NR4 7TJ, United Kingdom \\ ${ }^{6} \mathrm{CNR}$, Institute of Marine Sciences, AREA Science Park Q2 bldg., SS14 km 163.5, Basovizza, 34149 Trieste, Italy \\ ${ }^{7}$ National Institute of Oceanography and Applied Geophysics - OGS, via Beirut 2, 34151, Trieste, Italy \\ ${ }^{8}$ Joint Research Centre (JRC), European Commission, Ispra, Italy \\ ${ }^{9}$ Deptartment of Environmental Sciences, Informatics and Statistics, \\ University Ca' Foscari of Venice, Via Torino 155, 30172 Mestre, Italy \\ ${ }^{10}$ Marine Research Institute, Klaipeda University, Klaipeda, Lithuania \\ ${ }^{11}$ Abdus Salam ICTP, strada costiera 11, Trieste, Italy
}

Correspondence: Piero Lionello (piero.lionello@unisalento.it)

Received: 27 October 2020 - Discussion started: 13 November 2020

Revised: 21 May 2021 - Accepted: 11 June 2021 - Published: 1 September 2021

\begin{abstract}
Floods in the Venice city centre result from the superposition of several factors: astronomical tides; seiches; and atmospherically forced fluctuations, which include storm surges, meteotsunamis, and surges caused by atmospheric planetary waves. All these factors can contribute to positive water height anomalies individually and can increase the probability of extreme events when they act constructively. The largest extreme water heights are mostly caused by the storm surges produced by the sirocco winds, leading to a characteristic seasonal cycle, with the largest and most frequent events occurring from November to March. Storm surges can be produced by cyclones whose centres are located either north or south of the Alps. Historically, the most intense events have been produced by cyclogenesis in the western Mediterranean, to the west of the main cyclogenetic area of the Mediterranean region in the Gulf of Genoa. Only a small fraction of the inter-annual variability in extreme water heights is described by fluctuations in the dominant patterns of atmospheric circulation variability over the Euro-Atlantic sector. Therefore, decadal fluctuations in water height ex-
\end{abstract}

tremes remain largely unexplained. In particular, the effect of the 11-year solar cycle does not appear to be steadily present if more than 100 years of observations are considered. The historic increase in the frequency of floods since the mid19th century is explained by relative mean sea level rise. Analogously, future regional relative mean sea level rise will be the most important driver of increasing duration and intensity of Venice floods through this century, overcompensating for the small projected decrease in marine storminess. The future increase in extreme water heights covers a wide range, largely reflecting the highly uncertain mass contributions to future mean sea level rise from the melting of Antarctica and Greenland ice sheets, especially towards the end of the century. For a high-emission scenario (RCP8.5), the magnitude of 1-in-100-year water height values at the northern Adriatic coast is projected to increase by $26-35 \mathrm{~cm}$ by 2050 and by $53-171 \mathrm{~cm}$ by 2100 with respect to the present value and is subject to continued increase thereafter. For a moderateemission scenario (RCP4.5), these values are $12-17 \mathrm{~cm}$ by 2050 and $24-56 \mathrm{~cm}$ by 2100 . Local subsidence (which is not 
included in these estimates) will further contribute to the future increase in extreme water heights. This analysis shows the need for adaptive long-term planning of coastal defences using flexible solutions that are appropriate across the large range of plausible future water height extremes.

\section{Introduction}

This paper reviews current understanding of the factors that are responsible for the damaging floods affecting the Venice city centre and for their future evolution. The events of 4 November 1966, with estimated damages of EUR 400 million (De Zolt et al., 2006), and of 12 November 2019 (Cavaleri et al., 2020), with estimated damages above EUR 460 million (Godlewski et al., 2020) and extensive global media coverage, highlight the risks that future extreme floods bring. Potential damages have often been linked to future relative sea level (RSL) rise. Costs of EUR 7 billion have been estimated by the middle of this century if RSL rise continues at the rate observed in the 20th century (an unrealistic scenario based on recent trends and model projections) and can reach EUR 8 billion and EUR 16 billion for severe and highend RSL rise scenarios, respectively (Caporin and Fontini, 2016). These estimates ignore adaptation options but show the large exposure and the values at stake. In order to prevent damages and losses of a unique monumental and cultural heritage, in 1994 the Italian government approved the construction of a system of mobile barriers (MoSE, Modulo Sperimentale Elettromeccanico) to prevent the flooding of Venice. MoSE's construction was initiated in 2003, and it was successfully tested in October 2020.

The understanding of the dynamics leading to extreme floods and of the future evolution of their height and frequency is of paramount importance for a realistic assessment of present and future risks. This information is needed for efficient management of the implemented defence systems (see also Umgiesser et al., 2021, in this special issue), the assessment of their effectiveness from a climate change perspective, and the development of new strategies to cope with future scenarios (see also Zanchettin et al., 2021, and Lionello et al., 2021, in this special issue).

The city of Venice is located in the centre of a large and shallow lagoon (Fig. 1), covering $500 \mathrm{~km}^{2}$ with an average depth of about $1 \mathrm{~m}$. Water is exchanged between the lagoon and the open sea through three inlets (500-1000 m wide and from 8 to $17 \mathrm{~m}$ deep), and it propagates to the city centre along a complex pattern of very shallow areas and canals (from 2 to $20 \mathrm{~m}$ deep). The lagoon is separated from the sea by two long (about $25 \mathrm{~km}$ in total) narrow (less than $200 \mathrm{~m}$ average width) sandy barrier islands, reinforced with artificial defences in the most vulnerable parts. The elevation of these islands is such that they are not submerged during the most extreme events, with the exception of the 4 November 1966 flood, when they were breached at several points.

A clear relationship exists between the frequency of floods and RSL rise, resulting from the superposition of vertical land motion (at multiple spatial scales and timescales) and mean sea level (MSL) rise, which is projected to greatly increase flood risks in the future (e.g. Lionello et al., 2021). The RSL rise issue is extensively discussed in a complementary review article in this special issue (Zanchettin et al., 2021), to which the interested reader is referred for detailed information. However, RSL rise is not the only factor playing a role in flooding. Section 2.1 provides a general framework for the identification of the different factors acting at different timescales. Floods are caused by weekly to hourly atmospheric forcing, affected by long-term (seasonal to decadal) variability and intensified by the long-term (multi-decadal to centennial) RSL rise (Sect. 2.1). The timing of the surges produced by the atmospheric forcing with respect to the phase of astronomical tide and free oscillations (seiches) can substantially affect floods (Sect. 2.1 and 2.2). In fact, the length of the basin (Fig. 1) and the average speed of barotropic shallow-water waves combine in such a way that the period of the free oscillations is close to the diurnal and semidiurnal components. Therefore, the basin is close to resonant conditions, and the northern Adriatic has an astronomical tidal range of about $1 \mathrm{~m}$ at its coast, which is relevant for the floods of Venice. The combination of all these forcings largely explains the historical floods, which are to some extent heterogeneous in terms of the leading factors (see Sect. 2.2 and Appendix A).

Storm surges, which are particularly important because they often produce the largest contribution to the floods, are caused by cyclones (see Sect. 3.1). An important characteristic of the Adriatic Sea (particularly its northern area) is its proximity to the main cyclogenesis area of the western Mediterranean Sea, where cyclones initiate their southeastward propagation along the Mediterranean storm track and (in a small number of cases) towards central Europe (e.g.. Lionello et al., 2016). In autumn and winter, the area around the Adriatic Sea is frequently crossed by these cyclones. The resulting south-easterly wind (sirocco) when channelled along the main axis of the basin by the action of the Apennines and Dinaric Alps is essential for producing the storm surge in the northern Adriatic Sea and floods of Venice. At longer timescales, the frequency and/or severity of extreme water heights have also been associated with large-scale atmospheric variability and astronomical (solar) forcing. Available evidence of these links and their dynamics is reviewed in Sect. 3.2 and 3.3.

A major concern is the future evolution of floods. Section 4 is devoted to past and future changes in the frequency and magnitude of extremes and the relative roles of RSL rise and atmospheric forcing at different timescales. Section 4 also considers the most recent estimates of the future extremes and their dependence on the climate scenarios. Section 5 pro- 


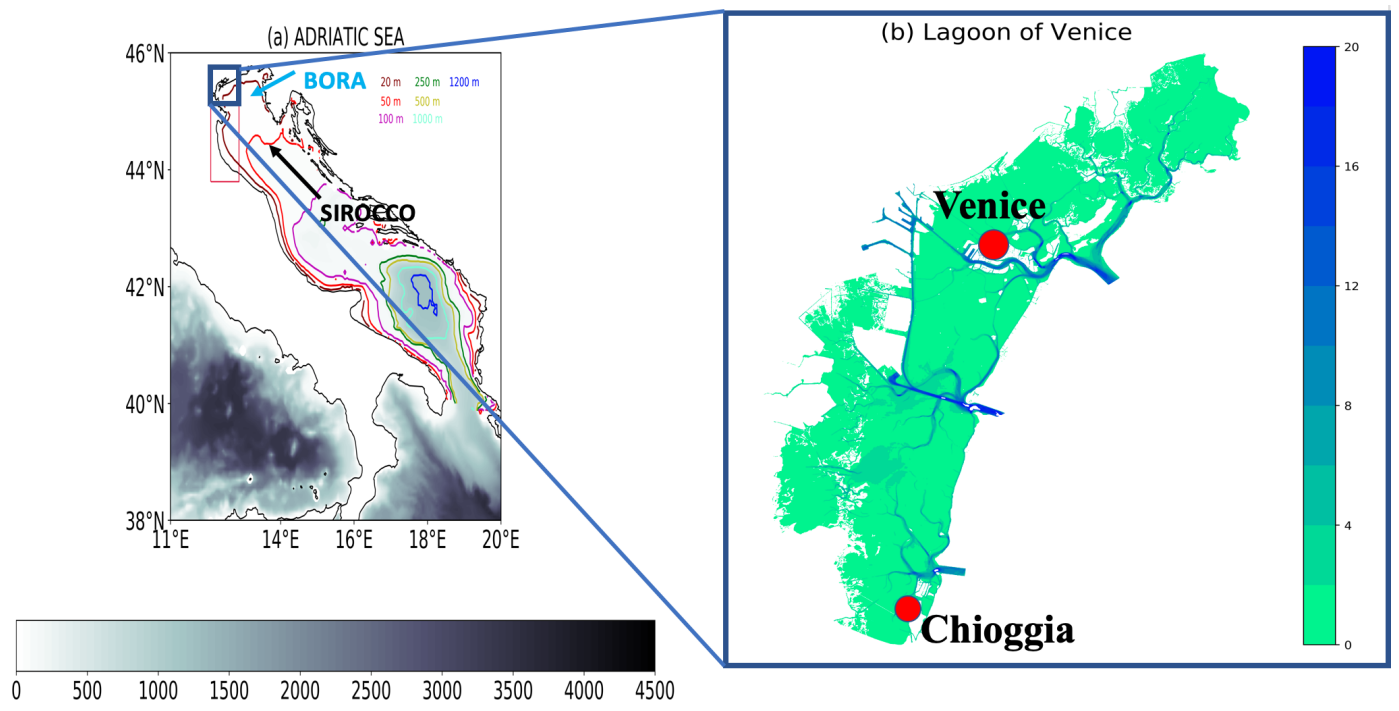

Figure 1. (a) Bathymetry of the Adriatic Sea with the position of Venice and arrows denoting the directions of the two main wind regimes affecting the northern Adriatic. The red box (whose northern part includes the whole lagoon) denotes the area represented by the data in Figs. 10 and 11. (b) Morphology of the Lagoon of Venice with the three inlets connecting it to the Adriatic Sea and the position of the city and of Chioggia (the bathymetric data are for the year 2002 and are based on original data provided by Magistrato alla Acque di Venezia and elaborated by Sarretta et al., 2010).

vides a general assessment of the existing knowledge as well as indications of major gaps and needs for future research.

\section{Dynamics and characteristics of extreme floods}

Extreme floods of Venice are caused by extremes or highend values of the local instantaneous thickness of the ocean, hereafter called water height. The water height is defined as the difference between the instantaneous sea level and a local reference level, both measured with respect to a fixed reference level (which could be the reference ellipsoid, the geoid, or a geocentric reference frame). In Venice, the local reference level moves vertically because of land subsidence. The water height and the total thickness of the water column differ by a constant value, which is the depth of the sea bottom with respect to the local reference level (Fig. 2). Water height extremes and sea level extremes differ because the latter do not consider the effect of subsidence, which is important in Venice. Water height extremes result from contributions with different timescales and characteristics that are described in the next subsection.

\subsection{Tides, seiches, and atmospherically forced sea level anomalies}

This section describes the factors that contribute to water height fluctuations in the northern Adriatic Sea: astronomical tides; seiches; and atmospherically forced fluctuations, which consist of meteotsunamis, storm surges, and surges caused by planetary atmospheric waves (PAWs) as well as inter-decadal to seasonal (IDAS) sea level variations and RSL rise. These factors are characterized by different dynamics and timescales. In general, they do not have the same importance in terms of contribution to extreme water heights, which have mostly been attributed to large storm surges, whose effect can be reinforced or attenuated by the remaining factors. The classification of the atmospherically forced fluctuations in three categories is based on the scale of the meteorological forcing process: mesoscale for meteotsunamis, synoptic scale for storm surges, and planetary scale for PAW surges (see Sect. 2.2). At longer timescales, inter-decadal, inter-annual, and seasonal (IDAS) sea level variability and local RSL rise also contribute to water height extremes. Local RSL rise is the increase in local sea level relative to the local solid earth surface (Fig. 2 and Gregory et al., 2019), and it can be directly estimated by averaging local tide gauge data over a conveniently long period. It is caused by vertical land movements and changes in local MSL. The evolution of the RSL and IDAS in Venice and of their different contributions is described in Zanchettin et al. (2021) in this special issue. The addition of storm surges, meteotsunamis, and PAW surges represents the meteorological surge contribution to the water height anomalies. The combined effect of seiches, astronomical tides, and meteorological surge is generically referred to as detrended water height in this paper (Fig. 2), meaning that variability at seasonal and longer timescales is subtracted.

Astronomical tides in the Adriatic Sea have a mixed semidiurnal cycle with two high and two low tide levels of different height every day. There are seven components with an 


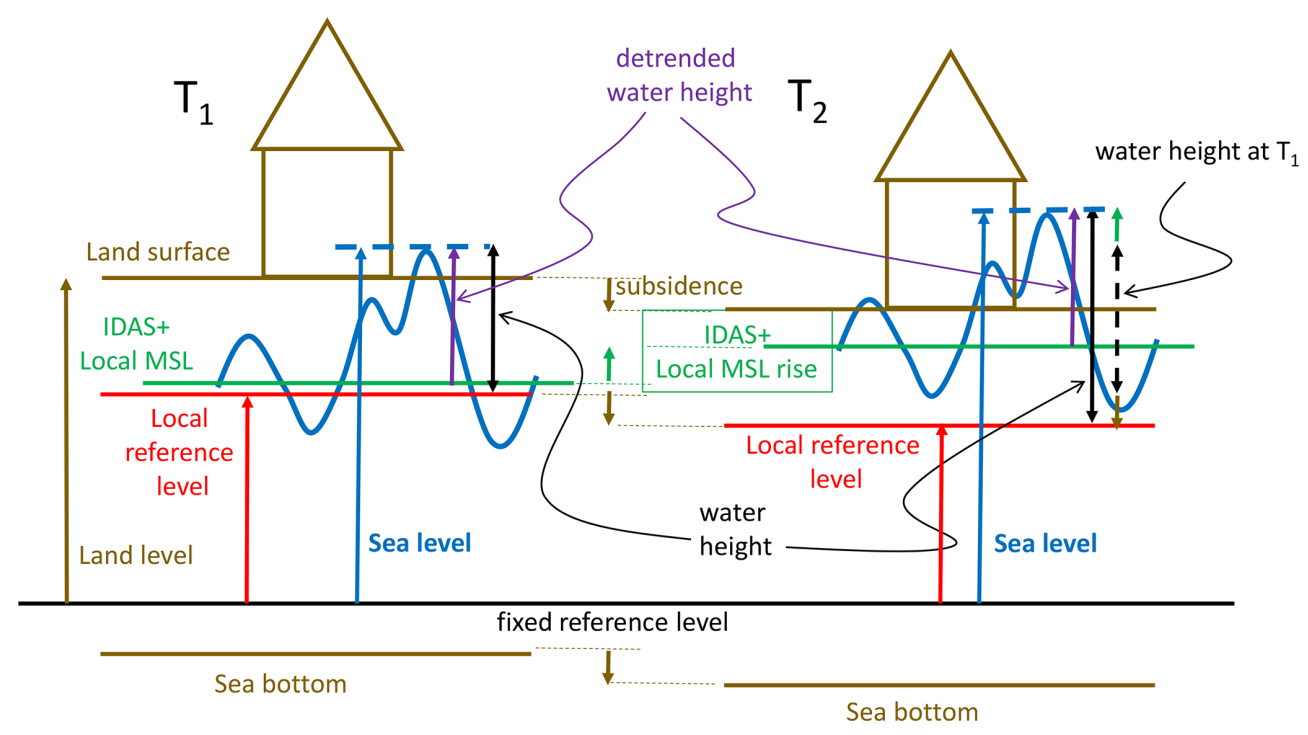

Figure 2. Schematic showing changes in water height for a hypothetical identical event occurring at time $T_{1}$ (mid-20th century) and $T_{2}$ (first decades of the 21 st century). Local subsidence has shifted the land surface, the reference level, and the sea bottom to a lower level. RSL rise and IDAS have shifted the sea surface to an upper level. The water height of the same event hypothetically measured at $T_{1}$ and $T_{2}$ differs by the IDAS and RSL rise contribution. The latter is split into local subsidence and mean sea level rise. The detrended water height is the addition of the meteorological surge (storm surge, PAW surge, meteotsunamis), astronomical tide, and seiches.

amplitude above $1 \mathrm{~cm}$ and only three above $10 \mathrm{~cm}$, with the semidiurnal $\mathrm{M}_{2}$ and $\mathrm{S}_{2}$, and diurnal $\mathrm{K}_{1}$ tides providing the largest contributions. The values of $\mathrm{M}_{2}, \mathrm{~S}_{2}$, and $\mathrm{K}_{1}$ are approximately 23,14 , and $16 \mathrm{~cm}$ both outside the lagoon and in the Venice city centre. Tides consist of two Kelvin waves oppositely travelling along the basin at semidiurnal periods (Hendershott and Speranza, 1971) and of topographic waves travelling across the basin at diurnal periods (Malačičet al., 2000). They are adequately reproduced by a number of numerical models (e.g. Janeković and Kuzmić, 2005; Lionello et al., 2005; Ferrarin et al., 2017). Both diurnal and semidiurnal components have their maximum amplitude at the northern shore of the basin, in association with antinodes of seiches (see below). The semidiurnal components have an amphidromic point in the centre of the Adriatic (Franco et al., 1982).

Storm surges in the Adriatic have been extensively studied due to the need to forecast the floods of Venice (Robinson et al., 1973; Umgiesser et al., 2020, in this issue for a review). The storm surge magnitude at the Venetian coast is mostly determined by the wind blowing over the shallow-water areas over the northern Adriatic Sea, whose contribution at the coast is typically 10 times larger than the inverse barometer effect (Bargagli et al., 2002; Conte and Lionello, 2013; Lionello et al., 2019). Storm surges are produced by two main wind configurations: sirocco blowing over the whole basin and a combination of bora over the northern Adriatic and sirocco over the southern Adriatic (Fig. 1). Depending on the structure of the wind field, flooding is more pronounced along the western or the eastern Adriatic coast (Međugorac et al., 2018).

Seiches in the Adriatic are standing waves with a node at the southern boundary of the basin and an antinode at the northern shore. The periods of the basic modes are estimated at about 21.3 and $10.8 \mathrm{~h}$ (Manca et al., 1974), and their patterns mimic those of the diurnal and semidiurnal tides, respectively. Seiches are commonly produced after a storm surge, when the wind drops or switches from sirocco (south-easterly) to bora (north-easterly), and the water accumulation in the northern Adriatic ceases to be supported by the wind stress. The Adriatic seiches are slowly damped, with the decay time of the fundamental mode amounting to $3.2 \mathrm{~d}$ (Cerovečki et al., 1997) due to a weak frictional dissipation inside the basin and a small energy loss to the Mediterranean Sea. There is a long tradition of numerical modelling of the Adriatic seiches (e.g. Lionello et al., 2005), but more accurate predictions of their periods and decay are still needed, (e.g. Bajo et al., 2019).

Meteotsunamis are meteorologically generated long ocean waves in the tsunami frequency band (Vilibić and Šepić, 2009; Šepić et al., 2009). They are generated by mesoscale atmospheric pressure disturbances that resonantly generate a travelling sea level anomaly when their speeds of propagation approach that of the shallow-water barotropic waves. Adriatic meteotsunamis pose a major hazard on the eastern Adriatic coast, where their resonant periods are close to those of the normal modes of the bays and harbours.

Long planetary atmospheric waves propagate slowly and with wavelengths ranging from 6000 to $8000 \mathrm{~km}$. They pro- 
duce a long-term meteorological forcing and eventually longlasting sea level anomalies (PAW surges), which establish favourable background conditions for flooding (Pasarić and Orlić, 2001).

The factors considered so far allow an interpretation of a typical flood ("aqua alta"; e.g. Robinson et al., 1973). When a cyclone moves from the western Mediterranean towards the Adriatic, low atmospheric pressure and sirocco wind support an increase in water height in the northern Adriatic Sea and potential flooding of the area. When the cyclone leaves the Adriatic area, atmospheric pressure increases, while the sirocco slackens or changes to bora. Consequently, sea level decreases and seiches may be generated. Therefore, in the Adriatic, storm surges and seiches represent two distinct phases of the response to the atmospheric forcing, one in which sea level rises under direct atmospheric forcing and the other in which sea level relaxes, possibly through a series of damped oscillations. If a successive storm surge develops before the attenuation of the seiches induced by a previous event, a constructive or destructive superposition may occur (Bajo et al., 2019). Analogously, the phase of tide during the period when the storm surge is large can substantially increase or decrease the actual sea level maximum. The contribution of meteotsunamis and PAW surges to extreme sea level events in Venice has not been thoroughly investigated to date. However, the recent 12 November 2019 event uncovered their important role in flooding in Venice (Ferrarin et al., 2021). Therefore, in general, the hazard and probability of an extreme sea level should also include these two contributions (see Sect. 2.2).

Water height values are further modulated by IDAS sea level variability (caused by changes in marine circulation, characteristics of the water masses, and the action of teleconnection patterns) and RSL changes. RSL changes represent a long-term process, and RSL rise has been the dominant factor responsible for the significant increase in frequency of floods of the Venice city centre (Lionello et al., 2012b). In the last century, it has been caused almost equally by the increase in the mean level of the sea surface and the decrease in the land level because of natural and anthropogenic subsidence (see Zanchettin et al., 2021, in this special issue, for a comprehensive review of its past and future evolution).

The floods of Venice do not occur because water overtops coastal barriers or defences. In fact, the elevation of the natural barriers separating the lagoon from the Adriatic Sea has so far prevented wave overtopping, with the unique exception (already mentioned in the Introduction) of the 1966 flood, when waves may have contributed to increased water height in the lagoon. Therefore, wave run-up and infragravity waves and nearshore processes (though certainly relevant along the seaside front of the barrier islands under some conditions) have never been considered when computing water height extremes inside the lagoon. It cannot be excluded that these factors will become relevant under extreme sea level rise in the future, but present evidence is that waves do not need to be considered for computing the water height in the Venice city centre (Roland et al., 2009) as long as barrier islands continue being protected by coastal defences and maintained by beach nourishment.

It is well known that tidal and non-tidal components have a certain degree of interaction in shallow-water areas with large tidal excursions where non-linear effects are significant (e.g Horsburgh and Wilson, 2007, and references therein). However, in a recent global-scale investigation on the nonlinear interactions between the tide and non-tidal residuals (Arns et al., 2020) only a small negative effect on extreme sea levels in the northern Adriatic Sea has been found. In fact, in the northern Adriatic Sea, given the relatively small importance of tidal excursions (about $1 \mathrm{~m}$ ) compared to the local water depth (average depth of about $35 \mathrm{~m}$ ), the effect of tides on the storm surge propagation has been neglected for a long time in the prediction practice with hydrodynamic models where only the meteorological forcing was used, and the astronomical tide was either added to the model results to get the actual prediction or subtracted from the observations for model validation. Examples of this approach and of its success are Lionello et al. (2006b), Bajo et al. (2007), and Mel and Lionello (2014) among many others. In fact, several high-resolution numerical studies have shown that tide-meteorological surge interactions are small, even during the most severe events (Roland et al., 2009; Cavaleri et al., 2019). An example of such simulations can be found in Appendix B, and it shows that in numerical simulations nonlinear interactions are lower than $5 \%$ at the peak of the water height.

\subsection{A description of the largest past events}

Regular tide gauge observations in Venice started in 1871. Since 1919 observations have been referenced to their mean level over the 1884-1909 period (central year 1897), which is the local reference level used for water height values and is usually called "Zero Mareografico Punta Salute" (ZMPS). The history of Venice tide gauges, their reference planes, and the related geodetic connections have been described and discussed by Dorigo (1961a). Battistin and Canestrelli (2006) reviewed the observations from 1872 to 2004 and provided a complete list of daily maxima and minima with the relevant primary data sources. Tide gauge data are also available on the websites of Istituto Superiore per la Protezione e la Ricerca Ambientale (ISPRA), Servizio Laguna di Venezia (https://www.venezia.isprambiente.it/, last access: 18 July 2021), and Centro Previsione e Segnalazione Maree of the Venice municipality (https://www.comune.venezia. $\mathrm{it} /$ it/content/centro-previsioni-e-segnalazioni-maree, last access: 1 August 2021).

The Venice Municipality defines large events ("aqua alta") as events when the water height exceeds $80 \mathrm{~cm}$ and severe and exceptional events as events when it exceeds 110 and $140 \mathrm{~cm}$, respectively. Since 1872, there have been 18 excep- 
Table 1. List of the extreme water heights (higher than $140 \mathrm{~cm}$ ) alongside the contributions (see Sect. 2.1 and 2.2): astronomical tide, seiches, storm surge, meteotsunami and mesoscale atmospheric variability (MAV) set-up, PAW surge, IDAS variability, relative mean sea level, meteorological surge, and total surge. The water height values are referenced to the "Zero Mareografico Punta Salute" (ZMPS). The upper panel shows the actual values $(\mathrm{cm})$, the lower panel the percentage $(\%)$ of each contribution.

\begin{tabular}{|c|c|c|c|c|c|c|c|c|c|c|}
\hline $\begin{array}{l}\text { Date and time } \\
\text { (yyyy-mm-dd time UTC) }\end{array}$ & $\begin{array}{l}\text { Water } \\
\text { height }\end{array}$ & $\begin{array}{r}\text { Astronomical } \\
\text { tide }\end{array}$ & Seiche & $\begin{array}{c}\text { Storm } \\
\text { surge }\end{array}$ & $\begin{array}{l}\text { Meteotsunami } \\
+ \text { MAV set-up }\end{array}$ & PAW surge & IDAS & $\begin{array}{l}\text { RSL (19-year } \\
\text { running mean) }\end{array}$ & $\begin{array}{r}\text { Meteorological } \\
\text { surge }\end{array}$ & $\begin{array}{r}\text { Detrended water } \\
\text { height }\end{array}$ \\
\hline \multicolumn{11}{|l|}{ Level (cm) } \\
\hline 1936-04-16 20:35:00 & 147 & 21 & 15 & 63 & 2 & 26 & 10 & 10 & 91 & 127 \\
\hline 1951-11-12 07:05:00 & 151 & 43 & 1 & 44 & 3 & 39 & 6 & 15 & 86 & 130 \\
\hline 1960-10-15 06:55:00 & 145 & 31 & 4 & 63 & 3 & 11 & 13 & 20 & 77 & 112 \\
\hline 1966-11-04 17:00:00 & 194 & -12 & 22 & 107 & 16 & 20 & 20 & 21 & 143 & 153 \\
\hline 1968-11-03 06:30:00 & 144 & 35 & 10 & 47 & 2 & 21 & 7 & 22 & 70 & 115 \\
\hline 1979-02-17 00:15:00 & 140 & 34 & -2 & 39 & 8 & 26 & 13 & 22 & 73 & 105 \\
\hline 1979-12-22 08:10:00 & 166 & 17 & 15 & 77 & 15 & 14 & 6 & 22 & 106 & 138 \\
\hline 1986-02-01 03:00:00 & 159 & 30 & 22 & 48 & 4 & 18 & 15 & 22 & 70 & 122 \\
\hline 1992-12-08 09:10:00 & 142 & 42 & 8 & 30 & 2 & 34 & 3 & 23 & 66 & 116 \\
\hline 2000-11-06 19:35:00 & 144 & 16 & 7 & 69 & 1 & 17 & 8 & 26 & 87 & 110 \\
\hline 2002-11-16 08:45:00 & 147 & 44 & -8 & 47 & 1 & 22 & 14 & 27 & 70 & 106 \\
\hline 2008-12-01 09:45:00 & 156 & 36 & 22 & 41 & 1 & 20 & 6 & 30 & 62 & 120 \\
\hline 2009-12-23 04:05:00 & 143 & 20 & 32 & 22 & 4 & 18 & 16 & 31 & 44 & 96 \\
\hline 2009-12-25 03:00:00 & 145 & 30 & 23 & 21 & 3 & 21 & 16 & 31 & 45 & 98 \\
\hline $2010-12-24$ 00:40:00 & 144 & 35 & 2 & 39 & 3 & 22 & 12 & 31 & 64 & 101 \\
\hline 2012-11-01 00:40:00 & 143 & 20 & 1 & 54 & 1 & 27 & 9 & 31 & 82 & 103 \\
\hline 2012-11-11 08:25:00 & 149 & 47 & -4 & 63 & 2 & 2 & 8 & 31 & 67 & 110 \\
\hline 2013-02-11 23:05:00 & 143 & 38 & 14 & 39 & 0 & 6 & 15 & 31 & 45 & 97 \\
\hline 2018-10-29 13:40:00 & 156 & 25 & 2 & 50 & 12 & 29 & 4 & 34 & 91 & 118 \\
\hline 2018-10-29 19:25:00 & 148 & -31 & 24 & 75 & 13 & 29 & 4 & 34 & 117 & 110 \\
\hline 2019-11-12 21:50:00 & 189 & 36 & 5 & 42 & 37 & 21 & 14 & 34 & 100 & 141 \\
\hline 2019-11-13 08:30:00 & 144 & 48 & 4 & 14 & 7 & 23 & 14 & 34 & 44 & 96 \\
\hline 2019-11-15 10:35:00 & 154 & 47 & 4 & 25 & 2 & 27 & 15 & 34 & 54 & 105 \\
\hline 2019-11-17 12:10:00 & 150 & 34 & 0 & 35 & 10 & 22 & 15 & 34 & 67 & 101 \\
\hline 2019-12-23 08:45:00 & 144 & 39 & 39 & 6 & 1 & 14 & 11 & 34 & 21 & 99 \\
\hline \multicolumn{11}{|l|}{ Percentage $(\%)$} \\
\hline 1936-04-16 20:35:00 & 147 & 14 & 10 & 43 & 1 & 18 & 7 & 7 & 62 & 86 \\
\hline 1951-11-12 07:05:00 & 151 & 28 & 1 & 29 & 2 & 26 & 4 & 10 & 57 & 86 \\
\hline 1960-10-15 06:55:00 & 145 & 21 & 3 & 43 & 2 & 8 & 9 & 14 & 53 & 77 \\
\hline 1966-11-04 17:00:00 & 194 & -6 & 11 & 55 & 8 & 10 & 10 & 11 & 74 & 79 \\
\hline 1968-11-03 06:30:00 & 144 & 24 & 7 & 33 & 1 & 15 & 5 & 15 & 49 & 80 \\
\hline 1979-02-17 00:15:00 & 140 & 24 & -1 & 28 & 6 & 19 & 9 & 16 & 52 & 75 \\
\hline 1979-12-22 08:10:00 & 166 & 10 & 9 & 46 & 9 & 8 & 4 & 13 & 64 & 83 \\
\hline 1986-02-01 03:00:00 & 159 & 19 & 14 & 30 & 3 & 11 & 9 & 14 & 44 & 77 \\
\hline 1992-12-08 09:10:00 & 142 & 30 & 6 & 21 & 1 & 24 & 2 & 16 & 46 & 82 \\
\hline 2000-11-06 19:35:00 & 144 & 11 & 5 & 48 & 1 & 12 & 6 & 18 & 60 & 76 \\
\hline 2002-11-16 08:45:00 & 147 & 30 & -5 & 32 & 1 & 15 & 10 & 18 & 48 & 72 \\
\hline 2008-12-01 09:45:00 & 156 & 23 & 14 & 26 & 1 & 13 & 4 & 19 & 40 & 77 \\
\hline 2009-12-23 04:05:00 & 143 & 14 & 22 & 15 & 3 & 13 & 11 & 22 & 31 & 67 \\
\hline 2009-12-25 03:00:00 & 145 & 21 & 16 & 14 & 2 & 14 & 11 & 21 & 31 & 68 \\
\hline 2010-12-24 00:40:00 & 144 & 24 & 1 & 27 & 2 & 15 & 8 & 22 & 44 & 70 \\
\hline 2012-11-01 00:40:00 & 143 & 14 & 1 & 38 & 1 & 19 & 6 & 22 & 57 & 72 \\
\hline 2012-11-11 08:25:00 & 149 & 32 & -3 & 42 & 1 & 1 & 5 & 21 & 45 & 74 \\
\hline 2013-02-11 23:05:00 & 143 & 27 & 10 & 27 & 0 & 4 & 10 & 22 & 31 & 68 \\
\hline 2018-10-29 13:40:00 & 156 & 16 & 1 & 32 & 8 & 19 & 3 & 22 & 58 & 76 \\
\hline $2018-10-29$ 19:25:00 & 148 & -21 & 16 & 51 & 9 & 20 & 3 & 23 & 79 & 74 \\
\hline 2019-11-12 21:50:00 & 189 & 19 & 3 & 22 & 20 & 11 & 7 & 18 & 53 & 75 \\
\hline 2019-11-13 08:30:00 & 144 & 33 & 3 & 10 & 5 & 16 & 10 & 24 & 31 & 67 \\
\hline 2019-11-15 10:35:00 & 154 & 31 & 3 & 16 & 1 & 18 & 10 & 22 & 35 & 68 \\
\hline 2019-11-17 12:10:00 & 150 & 23 & 0 & 23 & 7 & 15 & 10 & 23 & 45 & 67 \\
\hline $2019-12-23$ 08:45:00 & 144 & 27 & 27 & 4 & 1 & 10 & 8 & 24 & 15 & 69 \\
\hline Average & & 20 & 7 & 30 & 4 & 14 & 7 & 18 & 48 & 75 \\
\hline
\end{tabular}


tional events. Depending on the phase of the astronomical tide and on other factors, large water heights can or cannot correspond to very high storm surges. Table 1 lists the largest water heights ${ }^{1}$ alongside the contributions of various factors (in a similar way as previously done by Orlić, 2001):

\section{WATERHEIGHT $=$ STORM SURGE + PAW SURGE}

$$
\begin{aligned}
& + \text { METEOTSUNAMI and MAV set-up } \\
& + \text { ASTRONOMICAL TIDE + SEICHE } \\
& + \text { IDAS Variability + RSL. }
\end{aligned}
$$

In order to compute the values in Table 1, the long-term time series of Punta della Salute was processed with a tidal harmonic analysis tool based on the least squares fitting (Codiga, 2011) to separate the tidal from the other contributions. The residuals were detrended using a 10 -year centred running mean to determine the RSL rise.

The contributions of storm surge, PAW surge, meteotsunamis and mesoscale atmospheric variability (MAV), seiches, and IDAS variability have been estimated using digital bandpass filters in the time domain assuming Fourier decomposition, following Ferrarin et al. (2021). The procedure is straightforward for seiches and tides, which can be isolated by applying bandpass filters around their known frequencies. The criteria are more complicated when considering the response of sea level to the atmospheric forcing because it is characterized by a continuous spectrum. A general distinction by Holton (2004), based on the different spatial scales and timescales of the atmospheric phenomena, considers planetary-scale (order of $10^{7} \mathrm{~m}$ ), synopticscale (order of $10^{5}-10^{6} \mathrm{~m}$ ), and mesoscale (order of $10^{4}$ $10^{5} \mathrm{~m}$ ) motions. At the planetary scale, Rossby waves move westwards against the eastward zonal flow and are therefore characterized by relatively small speeds $\left(1-10 \mathrm{~m} \mathrm{~s}^{-1}\right)$ and long timescales (from 10 to $100 \mathrm{~d}$ ). Synoptic-scale systems (mostly driven by baroclinic instability) tend to move eastwards with the mean flow and are marked by relatively large speeds (typically $10 \mathrm{~m} \mathrm{~s}^{-1}$ ) and timescales of about a few days. Mesoscale systems (which are topographically forced or are driven by instabilities operating at that scale) have also relatively large speeds, of the order of $10 \mathrm{~m} \mathrm{~s}^{-1}$ (Markowsky and Richardson, 2010), and characteristic timescales in the range of $10 \mathrm{~min}$ to few hours. A $10 \mathrm{~d}$ period for the separation between planetary and synoptic scales is supported by the cross-spectral analysis of the $500 \mathrm{hPa}$ geopotential height and sea level for the Adriatic (Orlić, 1983), which show indeed high (low) coherence above (below) this threshold. A $10 \mathrm{~h}$ cut-off period allows the synoptic-scale and MAV setup (including meteotsunamis) to be distinguished as the latter has timescales in the range of the $10 \mathrm{~min}$ period of a pure buoyancy oscillation to the $17 \mathrm{~h}$ period of mid-latitude inertial oscillations (Markowsky and Richardson, 2010). On

\footnotetext{
${ }^{1}$ Some significant events may have been missed before 1933 due to lack of information, while all events are available since 1872.
}

a practical basis, Ferrarin et al. (2021) have used the $10 \mathrm{~h}$ threshold for separating responses to a cyclone moving in an eastward direction above the Mediterranean from a lowpressure mesoscale system travelling in a north-westward direction along the western Adriatic coast in their analysis of the 12 November 2019 event. The separation between PAW surges and IDAS variability was achieved by applying a lowpass filter with the cut-off period placed at $120 \mathrm{~d}$. The values of the contributions to water heights above $140 \mathrm{~cm}$ are shown in Table 1. Overall, the list agrees with the ones compiled in other studies since the beginning of instrumental observations (Dorigo, 1961b; Canestrelli et al., 2001). The frequency of water heights follows a strong seasonal cycle (Lionello et al., 2012). The most intense events (with maxima above the 99th percentile) occur in November and December, with the largest number of intense events concentrated in November. However, severe events (maxima above the 80th percentile) can occur from late September to early May and very rarely also in summer.

The event of 4 November 1966 corresponds to both the highest storm surge and the largest water height ever recorded in Venice. Other outstanding events are those observed on 22 December 1979 and 12 November 2019. The event of 29 October 2018 consists of two peaks separated by $6 \mathrm{~h}$, with similar water height values (148 and $156 \mathrm{~cm})$ but quite different phases of the astronomical tide so that the higher water level corresponds to the lower storm surge. This is the only example in 147 years of two such high water level peaks in such a short time interval. November 2019 is also peculiar because four water height peaks with at least $140 \mathrm{~cm}$ height occurred on 12,13,15, and 17 November. The event of 12 November 2019 was particularly severe, reaching $189 \mathrm{~cm}$. This was the second-highest water height ever recorded. In this case the storm surge was relatively modest, and the exceptional water level was caused by the superposition of PAW surges, positive astronomical tide, and an unprecedented contribution caused by a meteotsunami. After the exceptionally high water on 12 November, three successive events with water height above $140 \mathrm{~cm}$ occurred in just 5 d. As reported in Ferrarin et al. (2021), these events were driven by three separate sirocco wind episodes in the Adriatic Sea, which did not trigger any significant seiches. These flood events were determined by the overlapping of the maximum meteorological contribution, the tide peak, and a persistently high monthly mean sea level in the northern Adriatic. Four of the eight largest water heights since 1872 were observed during the autumn seasons of 2018 and 2019.

The astronomical tide is an important contribution to the actual water height extremes, and the time lag between the surge peak and the nearest astronomical tide maximum may make a substantial difference. Considering the events described in Appendix A, if surge and tide had peaked together, the observed water height, based on the linear superposition of the different factors (a reasonable first-order approximation for the Adriatic Sea), would have been approximately 
$220 \mathrm{~cm}$ on both 4 November 1966 and 29 October 2018 (second peak) and $215 \mathrm{~cm}$ on 12 November 1951. Particularly, for the second peak of 29 October 2018 the large negative contribution of the astronomical tide played an essential role limiting the severity of the event. In contrast, the coincidence of a moderate storm surge with a pre-existing seiche and a high astronomical tide level produced the sixth-highest water height in Table 1. In conclusion, storm surge often represents the largest contribution, but, in several cases, also other factors play a fundamental role. Particularly, in the case of 12 November 2019 (the second-highest water height ever recorded) several other factors exhibited contributions comparable to the storm surge, whose value was rather moderate.

The meteorological and marine conditions that led to major storm surge events have been assessed with reanalyses and dedicated model simulations, including the catastrophic storm surges of 4 November 1966 (De Zolt et al., 2006; Roland et al., 2009; Cavaleri et al., 2010), 22 December 1979 (Cavaleri et al., 2010), 1 December 2008 (Međugorac et al., 2016), 1 November 2012 (Međugorac et al., 2016), and 12 November 2019 (Ferrarin et al., 2021). Bertotti et al. (2011) modelled five important events that occurred between 1966 and 2008. Appendix A describes the largest water height events and related meteorological situations.

\subsection{The propagation of the sea level signal in the interior of the lagoon}

Northern Adriatic water height anomalies first propagate into the lagoon through the three inlets and then follow the tidal channels (Fig. 1, right panel). The major channels inside the lagoon are up to $10 \mathrm{~m}$ deep, and this results in a propagation speed of about $10 \mathrm{~m} \mathrm{~s}^{-1}$ (Umgiesser et al., 2004). The water then expands laterally into the shallow flats, where propagation of the wave is much slower. Astronomical tides in the southern and central basins of the lagoon are slightly amplified with respect to the inlets because of resonance effects between the tide (both diurnal and semidiurnal) and the size of the basin. In the northern part of the lagoon, characterized by mud flats, islands, and salt marshes, dissipative processes dominate over the resonance condition so that the tidal wave shows an attenuation of about $50 \%$ of the incoming tide (Ferrarin et al., 2015). As a consequence of natural and anthropogenic morphological changes that occurred in the lagoon in the last century, the amplitude of major diurnal and semi-diurnal tidal constituents grew significantly, with a consequent increase in extremely high sea levels in Venice (Ferrarin et al., 2015).

The surge signal, once it has entered the lagoon, propagates nearly without damping to the city centre, where water levels are comparable to the ones close to the inlets, with a typical $1 \mathrm{~h}$ delay (Umgiesser et al., 2004). Other more remote areas of the lagoon show a higher phase shift with respect to the inlets of up to $3 \mathrm{~h}$. With strong NE (bora) or SE (sirocco) winds, the difference between water levels on the southern

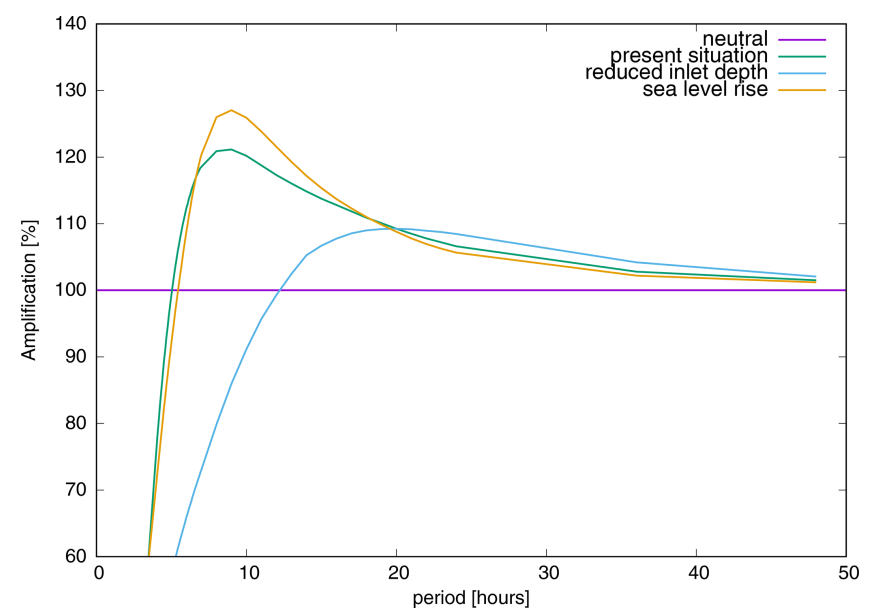

Figure 3. Amplification (percentage, $y$ axis) of sea level oscillations in the Venice city centre with respect to their amplitude at the lagoon inlets as a function of their period (hours, $x$ axis). The curves show the present situation (green), a hypothetical reduction to $6 \mathrm{~m}$ of the depth of the three inlets of the lagoon (light blue), and an RSL rise of $1 \mathrm{~m}$ without any change in the morphology of the lagoon (yellow). Values higher (lower) than 100 (shown for reference) correspond to amplification (attenuation).

and the northern side of the lagoon may exceed $50 \mathrm{~cm}$ (Mel et al., 2019). The Venice city centre is relatively little affected by these differences since it is close to the node of the oscillations. However, the strong set-up at the southern part of the lagoon can lead to flooding in the city of Chioggia.

Figure 3 shows the amplification factor (percentage; values higher (lower) than 100 correspond to amplification (attenuation)) of sea level oscillations in the Venice city centre with respect to their amplitude at the lagoon inlets as a function of their period. This computation is based on the model of Umgiesser et al. (2004). In the present situation, longperiod oscillations $(\geq 24 \mathrm{~h})$ at the inlets propagate undisturbed into the lagoon, short ones $(\leq 3 \mathrm{~h})$ are very effectively damped, and at intermediate periods they reach an amplification maximum of about $120 \%$ at $9 \mathrm{~h}$. Numerical experiments with the same model and no friction suggest that this effect is caused by the combination of internal resonances occurring in the range of 10 to $5 \mathrm{~h}$ with the strong friction inside the shallow lagoon. In the hypothetical case with very shallow inlets (maximum depth equal to $6 \mathrm{~m}$ ), all periods below $12 \mathrm{~h}$ are heavily damped. This shows that lowering the depth of the inlets would lower the water height maxima inside the lagoon, though with problematic consequences in terms of reduced shipping, water exchange, and strong erosion inside the inlets. A $1 \mathrm{~m} \mathrm{RSL}$ rise (without any change in the morphology of the lagoon) would amplify the lagoon response, showing the possibility of higher extremes in the future. 


\section{Atmospheric patterns associated with extreme storm surges}

\subsection{Characteristics of cyclones producing storm surges and floods of Venice}

The Mediterranean region is characterized by a high frequency of cyclones due to a wide range of factors and mechanisms that favour cyclogenesis (Trigo et al., 1999; Lionello et al., 2006a; Ulbrich et al., 2009; Lionello et al., 2012a; Ulbrich et al., 2012; Lionello et al., 2016). These systems are often associated with extreme weather events (Jansa et al., 2014; Lionello et al., 2006a; Toreti et al., 2010; Ulbrich et al., 2012; Reale and Lionello, 2013), storm surges along the Mediterranean coastline, and floods of Venice (Canestrelli et al., 2001; Trigo and Davies, 2002; De Zolt et al., 2006; Lionello et al., 2012b; Lionello et al., 2019). Cyclones produce storm surges by two mechanisms: the inverse barometric effects caused by the decrease in atmospheric pressure during their transit over the area and the wind set-up caused by the intense surface wind that piles up water masses against the coast of the northern Adriatic (Lionello et al., 2019).

Figure 4 shows the temporal evolution of mean sea level pressure (MSLP) and $10 \mathrm{~m}$ wind fields during intense storm surge events. It is a composite based on the floods with a storm surge contribution higher than $50 \mathrm{~cm}$ in the period 1979-2019 (Table 1) using ERA5 reanalysis (Hersbach et al., 2020). The time lags chosen for the composites are 36, 24, and $12 \mathrm{~h}$ before and 12 and $24 \mathrm{~h}$ after the peak of the events reported in Table 1. Figure 5 shows the same information, though it is based on the remaining events in Table 1 (with a storm surge contribution lower than $50 \mathrm{~cm}$ ). In both figures the pressure minimum is located in the Gulf of Genoa at the peak of the event, but in Fig. 4 the cyclone is deeper, and the MSLP gradient along the Adriatic Sea is larger. These differences have strong impacts on the intensity of the wind fields, their spatial structure, and direction in the Adriatic Sea (small panels in Figs. 4 and 5), modulating the part of the Adriatic coastline that is most affected by the storm surge (Međugorac et al., 2018). Indeed, the first predictions of floods in Venice were based on an autoregressive model considering as inputs the MSLP cross-basin differences (Tomasin and Frassetto, 1979). Further, the evolution of the cyclone before and after the water peak of the storm surge is different in Figs. 4 and 5. In Fig. 4 cyclogenesis occurs close to the Iberian coast in the western Mediterranean Sea (as noted in Lionello et al., 2012b), with an MSLP minimum well separated from the background field. In Fig. 5 cyclogenesis occurs in the northwestern Mediterranean Sea within the flow produced by a pre-existing cyclone, whose centre is located north of the Alps. In both composites the lee cyclogenesis processes and the generation of a secondary minimum are evident (Trigo and Davies, 2002; Lionello, 2005; Lionello et al., 2012b; Lionello et al., 2019), and the pressure gradient along the Adriatic Sea intensifies and becomes almost parallel to the basin coastlines. This synoptic configuration produces a decrease in the atmospheric pressure above northern Italy and an increase in intensity of the atmospheric flow in the Adriatic Sea directed towards its northern coast, which results in the increase in sea level in Venice.

Figure 6 shows the density (contours) of tracks of cyclones (measured in percentage relative to the total frequency of cyclones in each cell of $1.5^{\circ}$ ) producing a water height higher than $110 \mathrm{~cm}$ (https://www.comune.venezia.it/ it/content/grafici-e-statistiche, last access: 8 August 2021) in the period 1979-2019. Figure 6 also reports the tracks of the cyclones associated with all events that are listed in Table 1 (cyan colour), with the events of 4 November 1966, 29 October 2018 (Vaia storm), and 12 November 2019 in blue, red, and green lines, respectively. Cyclone tracks shown in Fig. 6 have been identified with an automatic detection and tracking scheme (Lionello et al., 2002) applied to the ERA5 MSLP fields at a spatial resolution of $0.25^{\circ}$ and a temporal resolution of $6 \mathrm{~h}$. The tracking scheme partitions the MSLP fields in depressions, which can be considered candidates for independent cyclones, by merging all steepest descent paths leading to the same pressure minimum. Shallow secondary minima with a small area are absorbed in the nearest large system, whose trajectory is computed by associating the location of the low-pressure centres in successive maps within a minimum distance criterion until the system disappears (cyclolysis). In that way, the method detects the formation of cyclones inside the Mediterranean and, at the same time, avoids the inflation in the number of cyclones that would result from considering small, short-lived features as independent systems. This method has been extensively described in previous works (Lionello et al., 2002; Reale and Lionello, 2013; Lionello et al., 2016) and already used in numerous studies assessing the climatology of Mediterranean cyclones, such as Lionello et al. (2016), Flaounas et al. (2018), the IMILAST (Intercomparison of MId-LAtitude STorm diagnostics) tracking scheme intercomparison analysis (Neu et al., 2013), and a dedicated study on the synoptic patterns leading to high water levels along the coast of the Mediterranean Sea (Lionello et al., 2019). Readers are referred to those studies for details. The density of tracks shown in Fig. 6 is characterized by a north-western-southeastern direction in the Atlantic sector, which is different from the usual south-western-north-eastern pattern of the regional storm track (Neu et al., 2013; Ulbrich et al., 2013; Reale et al., 2019). Moreover, it has a maximum in the western Mediterranean. As also shown in Lionello et al. (2012) the tracks of cyclones producing the largest floods (Table 1 and Fig. 3) have distinctive characteristics with respect to the majority of cyclones crossing the Mediterranean Sea. Many of these systems enter the region from the west-south-west and follow a north-eastward direction. Differently, the majority of Mediterranean cyclones originate in the Gulf of Genoa and follow a south-eastern direction (Trigo et al., 2002, 1999; Lionello et al., 2006a; Ulbrich et al., 2012; Lionello et al., 

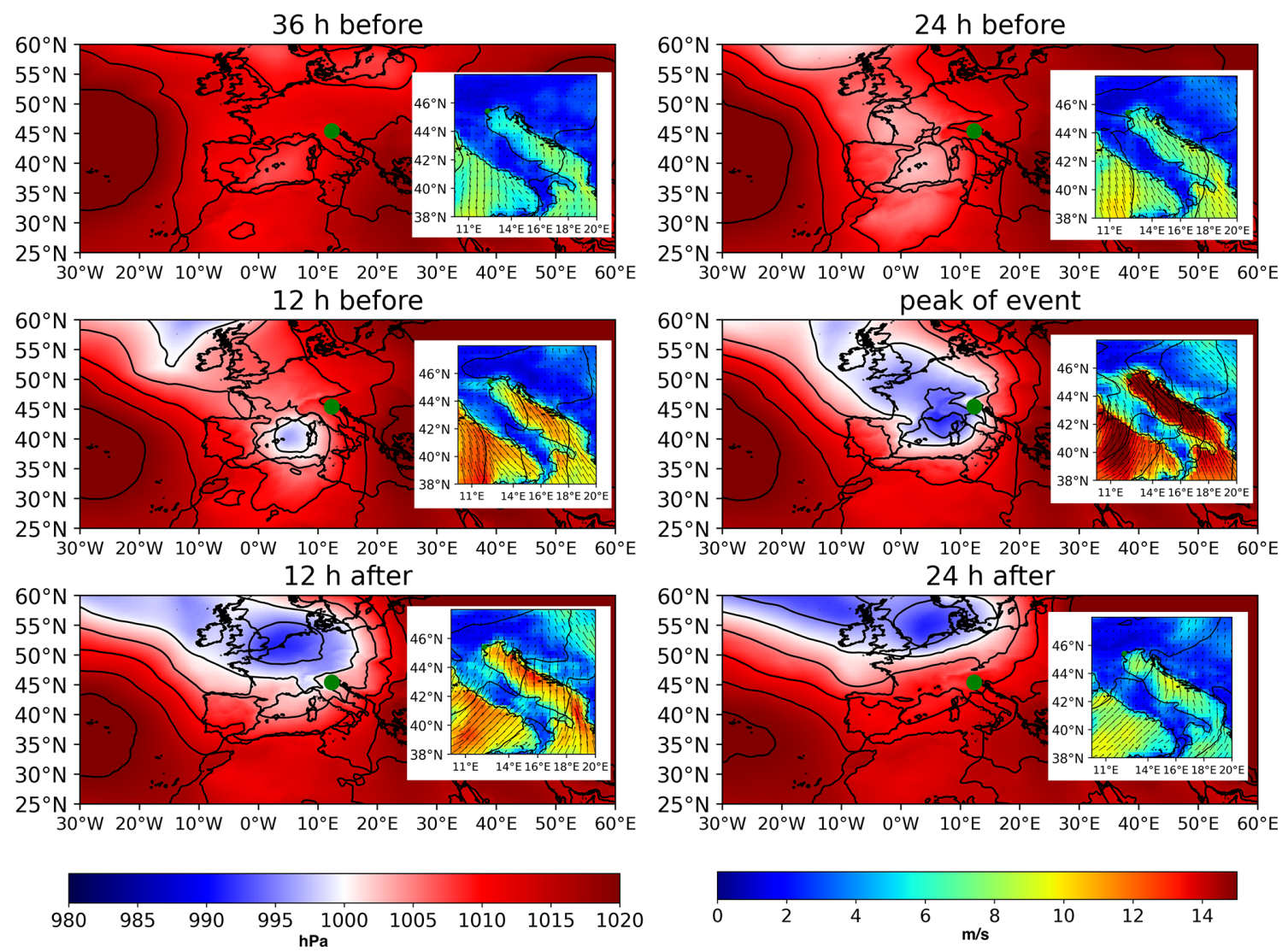

Figure 4. Large panels show the composite of MSLP fields based on ERA5 (hPa; left colour bar) datasets associated with storm surges higher than $50 \mathrm{~cm}$ in Venice (see Table 1). Small panels show the corresponding wind fields over the Adriatic Sea ( $\mathrm{m} \mathrm{s}^{-1}$; right colour bar). The time lags chosen for the composites are 36, 24, and $12 \mathrm{~h}$ before and 12 and $24 \mathrm{~h}$ after the peak of the event. The green dot shows the location of the city of Venice.

2016). In fact, the position of the pressure minimum, the spatial structure of cyclone-induced wind fields over the Adriatic Sea, and the MSLP cross-basin differences largely affect the characteristics of the storm surge. More recent studies confirm that the position of the cyclone with respect to the basin is critical for storm surges in the northern Adriatic, and its variation induces a veering of the onshore wind and even negative responses in sea level (Lionello et al., 2019).

The peculiarity of cyclones triggering storm surges is also evidenced from a cluster analysis of the daily atmospheric fields associated with the peaks above the 99.5th percentile of the daily mean detrended water height obtained with a 6-month high-pass filter (Fig. 7). Only peaks that are separated by at least $3 \mathrm{~d}$ are considered to ensure the selection of independent extreme events. To ensure a large sampling size, the analysis uses the NCEP/NCAR reanalysis data for the 1948-2018 period (Kalnay et al., 1996). A $k$-means clustering (e.g. Wilks, 2011) of the standardized anomalies of MSLP over the Euro-Atlantic sector and $10 \mathrm{~m}$ wind vectors over the Mediterranean Sea has been applied to group events with similar spatial patterns. Clusters are constructed so that differences between the daily patterns are minimized within the same cluster and maximized between the clusters, using the sum of squared distances as a metric. Each cluster is characterized by its centroid (the composited spatial pattern of MSLP and $10 \mathrm{~m}$ wind standardized anomalies for all days in the cluster). The root mean square difference (RMSD) between the daily standardized fields of MSLP and $10 \mathrm{~m}$ wind vector of all considered events and their corresponding centroid measures the total spread of the partition. When all extremes are considered (Fig. 6a), the resulting centroid pattern resembles that of Figs. 4 and 5 at the peak of the event. However, the composite has a considerable spread (large RMSD), which can be reduced by progressively discriminating types of events (i.e. increasing the number of clusters; Fig. 6b). Two clusters bring the steepest decrease in the RMSD distribution and capture the distinction between cyclones to the north and south of the Alps (Figs. 7c, d) already reported by Lionello (2005).

\subsection{Links to large-scale patterns}

Several studies have investigated links between the main modes of atmospheric circulation variability and floods in 

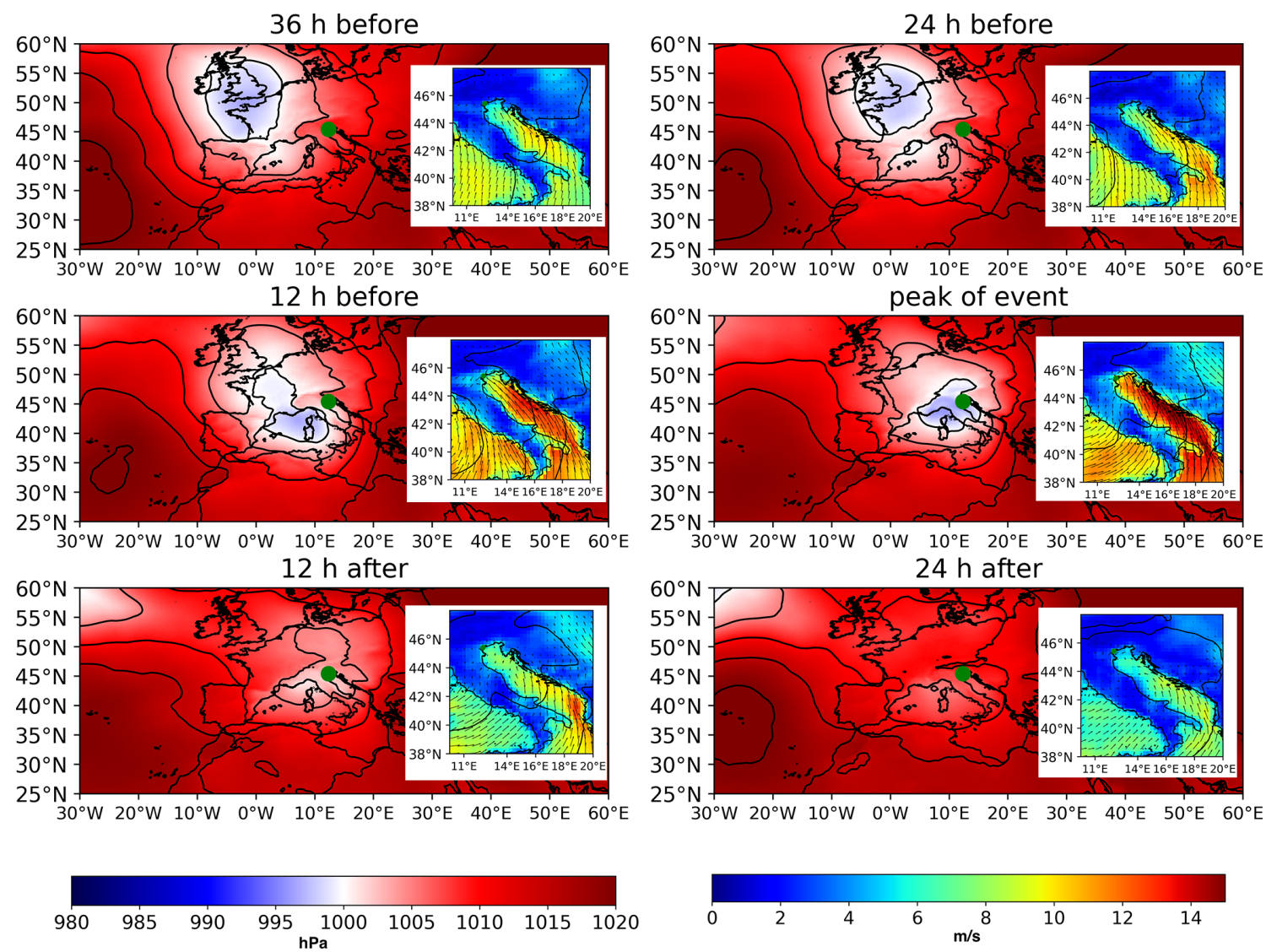

Figure 5. Same as Fig. 2, except it is based on the events in Table 1 with storm surge height lower than $50 \mathrm{~cm}$.

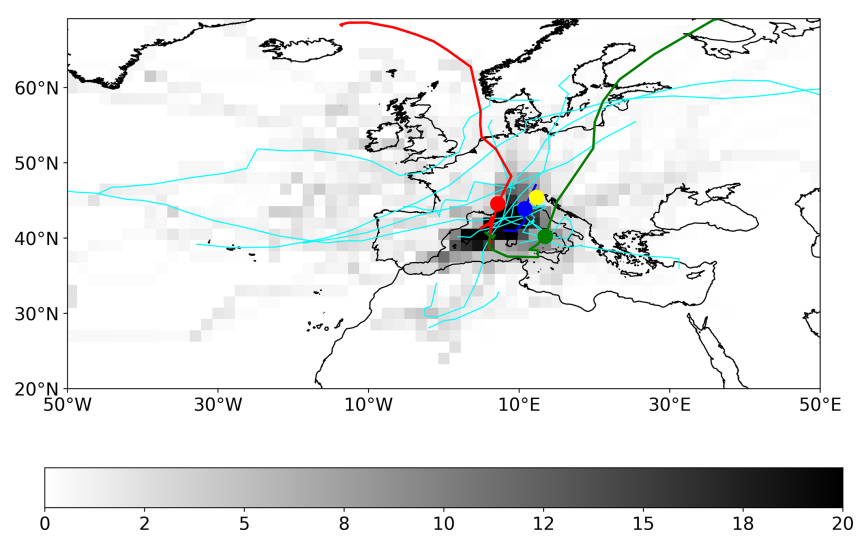

Figure 6. Density of tracks of cyclones associated with storm surges contributing to water height maxima above $110 \mathrm{~cm}$ (relative frequency of cyclones for each cell of 1.5 in percentage of total; grey bar in the panel; based on ERA5). Cyan tracks represent the events reported in Table 1 with water height maxima of $140 \mathrm{~cm}$ (see Table 1); the red, green, and blue tracks represent the 29 October 2018 , 12 November 2019, and 4 November 1966 events (the blue track is based on ERA40 data). The yellow dot represents the location of the city of Venice.
Venice (Fagherazzi et al., 2005; Lionello, 2005; Zanchettin et al., 2009; Barriopedro et al., 2010; Martínez-Asensio et al., 2016). The negative phase of the North Atlantic Oscillation (NAO) has been associated with both high mean sea level and floods in Venice (Zanchettin et al., 2009), although this signal is absent in autumn (when storm surges are larger). Indeed, the large-scale circulation pattern associated with Venice floods (Lionello, 2005) is different to the NAO, the East Atlantic (EA; Martínez-Asensio et al., 2014, 2016) and the East Atlantic-Western Russia (EAWR; Fagherazzi et al., 2005) being the teleconnection patterns that exert the largest influence on their seasonal characteristics. Differences in the large-scale seasonal mean atmospheric circulation between active years (autumns with at least one large meteorological surge $^{2}$ ) and quiet years (autumns with no large meteorological surge) have also been reported (Barriopedro et al., 2010). The favourable seasonal pattern for the occurrence of large meteorological surges in autumn displays little resemblance to the NAO but a negative pressure centre in central Europe, similar to that found in the daily based composite of Fig. 7a.

The aforementioned relationships are often weak, though, and hence potentially sensitive to metrics, thresholds, and

\footnotetext{
${ }^{2}$ Events in which the meteorological surge exceeds the 95 th percentile of the total distribution.
} 

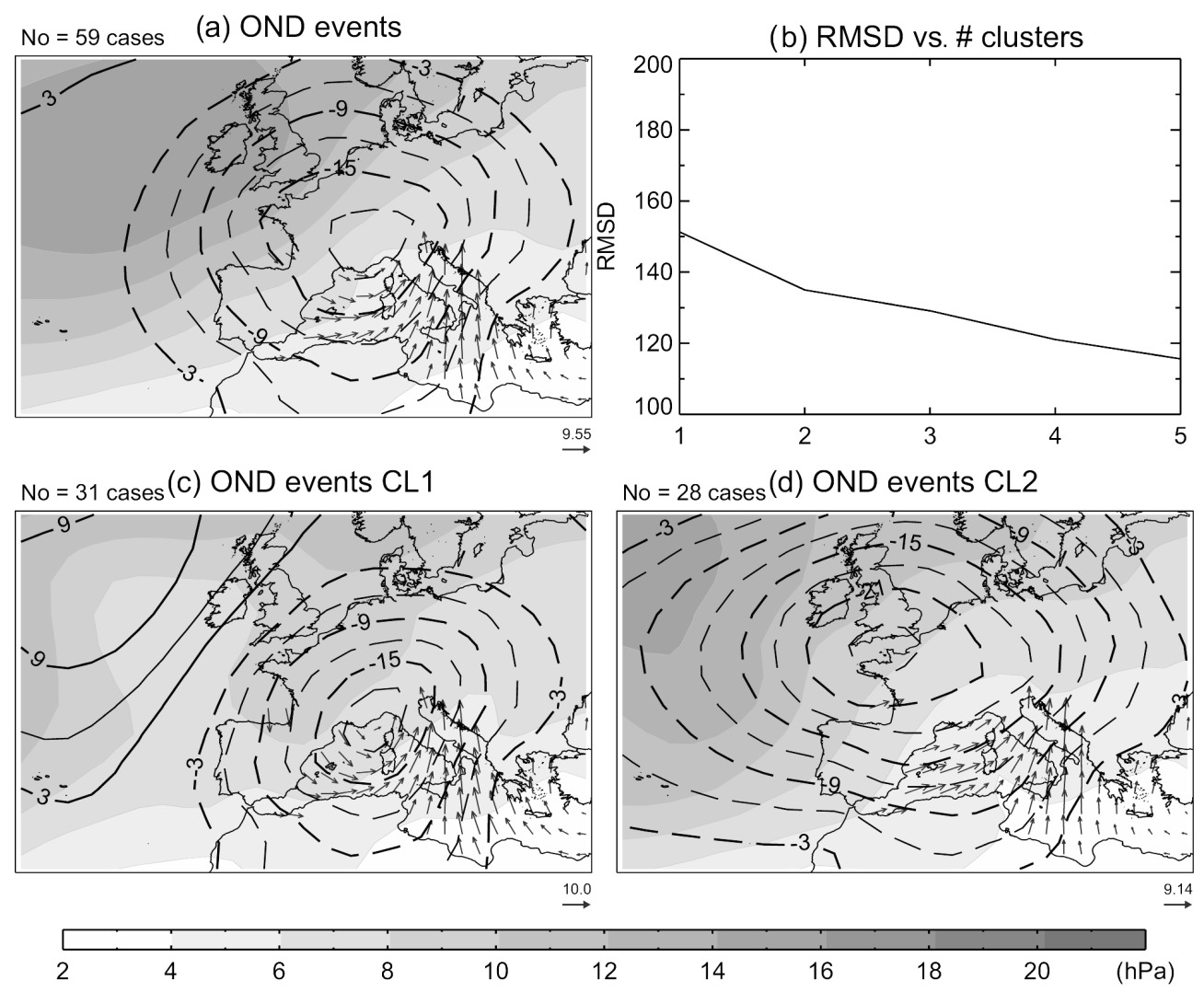

Figure 7. (a) Composite of daily anomalies of sea level pressure (MSLP) over $[30,60]^{\circ} \mathrm{N},\left[30^{\circ} \mathrm{W}, 30^{\circ} \mathrm{E}\right]($ contours, hPa) and $10 \mathrm{~m}$ wind vector over the Mediterranean Sea (arrows, $\mathrm{ms}^{-1}$ ) for autumn (October-November-December, OND) daily mean detrended water heights above the 99.5th percentile of the 1948-2018 distribution. Shading shows the standard deviation of the composited MSLP fields. The number of cases is shown in the top left corner. The modulus of a reference wind speed vector is shown in the bottom right corner. (b) Root mean square difference (RMSD) of the daily standardized anomalies of MSLP and $10 \mathrm{~m}$ wind vector as a function of the number of clusters. RMSDs are computed with respect to the centroid of the respective cluster. (c, d) As (a) but when surge events are split in two groups, which are referred to as cluster one (CL1) and two (CL2) and correspond to the choice of two clusters in (b). Note that (a) is equivalent to one cluster with all events. Data sources: NCEP/NCAR reanalysis (Kalnay et al., 1996).

analysed periods. This blurred influence of teleconnection patterns is not surprising, taking into account that seasonally averaged indices do not necessarily capture short-term fluctuations and that favourable synoptic conditions (see Fig. 7) might occur under different large-scale configurations. To avoid this, a weather regime (WR) approach is adopted herein, which predefines a number of recurrent large-scale atmospheric circulation patterns and assigns each day to one of them. Following (Garrido-Perez et al., 2020), we considered eight WRs, which yield a fair representation of the variability year-round. Almost half of the extreme events ${ }^{3}$ in Venice are associated with the Atlantic low (AL) WR (Fig. 8a), whose canonical pattern (Fig. 8b) strongly resembles that of Fig. 7d and of Fig. 8.6 of Lionello (2005). The remaining cases (arguably many of the Mediterranean cyclones included in Fig. 7c) occur under different WRs with-

\footnotetext{
${ }^{3}$ Events with daily mean detrended water height above the 99.5th percentile of the 1948-2018 distribution.
}

out a clear preference, although some anticyclonic WRs (e.g. the Atlantic high) are unfavourable for extreme meteorological surges. Despite the strong association with AL on daily scales, the Spearman's rank correlation $r$ between the seasonal frequency series of AL days and extreme events is low $(r=0.26$ for $1948-2018, p<0.05$, where $p$ is the significance level) and similar to that obtained from other less influential WRs (e.g. zonal regime; $r=0.27, p<0.05$ ). This illustrates that the inter-annual variability in detrended water height extremes in autumn cannot be well described by fluctuations in the dominant patterns of atmospheric circulation variability over the Euro-Atlantic sector.

\subsection{The role of solar cycles in extreme floods}

Some studies have reported decadal fluctuations in the frequency of floods in phase with the 11-year solar cycle during the second half of the 20th century, such that periods of high solar activity have coincided with more frequent and 
(a) OND events \& WRs

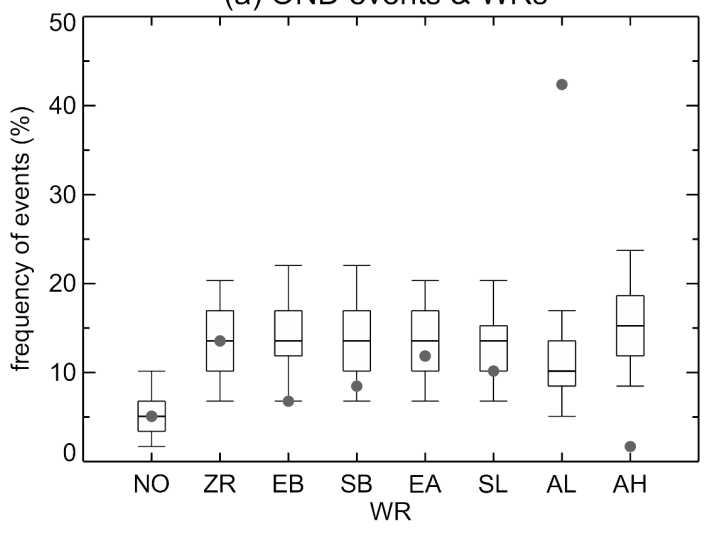

(b) OND AL

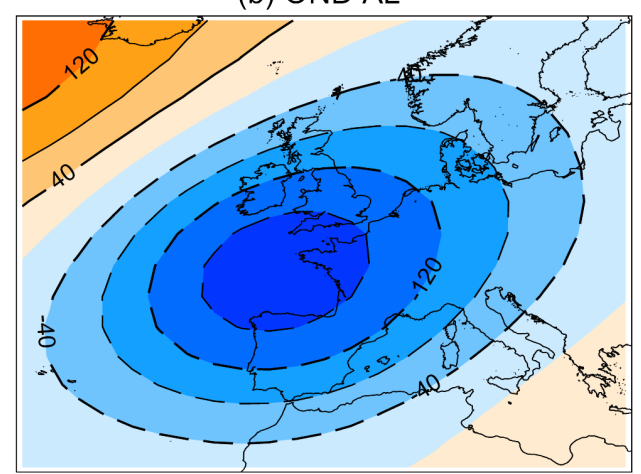

Figure 8. (a) Relative frequency of autumn extreme daily mean detrended water heights above the 99.5th percentile of the 1948-2018 (in per cent with respect to the total number of events) occurring under the given weather regime (WR). Whiskers denote the random distributions obtained from a bootstrap of 5000 trials, each one containing the same number of autumn days of the 1948-2018 period as surge events. Boxes denote the inter-quartile distribution, with the median in between, and bars extend from the 5th to the 95th percentile of the random distributions. WRs are defined from daily fields of geopotential height at $500 \mathrm{hPa}$ of the NCEP/NCAR reanalysis over the Euro-Atlantic sector $[30,65]^{\circ} \mathrm{N},\left[30^{\circ} \mathrm{W}, 25^{\circ} \mathrm{E}\right]$. Abbreviations are as follows: $\mathrm{NO}$ - no (i.e. undefined) WR, ZR - zonal regime, EB - European blocking, SB - Scandinavian blocking, EA - East Atlantic, SL - Scandinavian low, AL - Atlantic low, AH Atlantic high. See Garrido-Pérez et al. (2020) for further details. (b) The AL pattern that is associated with the occurrence of more than $40 \%$ of extremes. Data sources: NCEP/NCAR reanalysis (Kalnay et al., 1996).

persistent floods in Venice (Tomasin, 2002; Lionello, 2005; Barriopedro et al., 2010) and other Mediterranean coastal stations (Martínez-Asensio et al., 2016). This signal results from the atmospheric forcing on sea level, as revealed by hindcasts of a barotropic ocean model forced with observed atmospheric pressure and winds (Martínez-Asensio et al., 2016).

An unanswered question is how such a small solar forcing could modulate the tropospheric circulation over the Euro-
Atlantic sector. Several hypotheses have been proposed, including decadal variations in the regional atmospheric circulation that promote the constructive interference with the favourable pattern for the occurrence of extreme floods during periods of high solar activity (Barriopedro et al., 2010). Other studies claim a solar modulation of the stratospheric polar vortex and a lagged response of the NAO (e.g. Thiéblemont et al., 2015, and reference therein). However, this mechanism would mainly affect the winter NAO rather than the decadal variability in autumn floods in Venice. In addition, modelling studies reveal negligible impacts of the 11year solar cycle on the NAO and demonstrate that decadal variations in the NAO can eventually vary in phase with the 11-year solar cycle by random chance (Chiodo et al., 2019). Given the lack of mechanistic understanding, the null hypothesis of internal variability cannot be rejected.

Indeed, an updated analysis of autumn extreme events (99.5th percentile) from the longest series of daily mean detrended water height in Venice based on the data of Raicich (2015), covering the period 1872-2018, shows that the 11-year solar signal has not been evident since the $~$ 2000s, nor was it present before the $\sim 1950$ s (Fig. 9, top panel). Significant correlations are limited to the period from 1970 to 2000 (Fig. 9, bottom panel) and give rise to strong co-variability during the second half of the 20th century, coinciding with the grand solar maxima covered by most studies. Further, there is no indication of the presence of an 11year periodicity in the series of autumn mean water height (Fig. $\mathrm{C} 1$ in Appendix C) and when extreme events are defined using different thresholds (Fig. C2 in Appendix C). These results suggest that if there is a solar signal it would likely be non-stationary (arguably masked by other sources of variability) and/or non-linear (e.g. confined to grand maxima of solar activity). The alternative hypothesis is that the decadal variability in extreme surges is due to other causes, including internal variability. It is plausible that, superimposed on the uncontroversial increasing frequency of Venice flooding due to the RSL rise, the frequency of extreme water heights will experience large inter-annual to decadal variations in the future, as has been observed in the recent period. However, the causes of this variability are still uncertain.

\section{Past and future evolution}

\subsection{Past evolution and recent trends of floods and extreme sea levels}

Enzi and Camuffo (1995) presented the most complete compilation of pre-instrumental extreme water heights observed in Venice by reviewing hundreds of historical documents, thus obtaining a sequence of over 100 events in the 7871867 period. The long-term evolution has been studied by Camuffo and Sturaro (2004), combining information from documentary sources and instrumental observations. From 


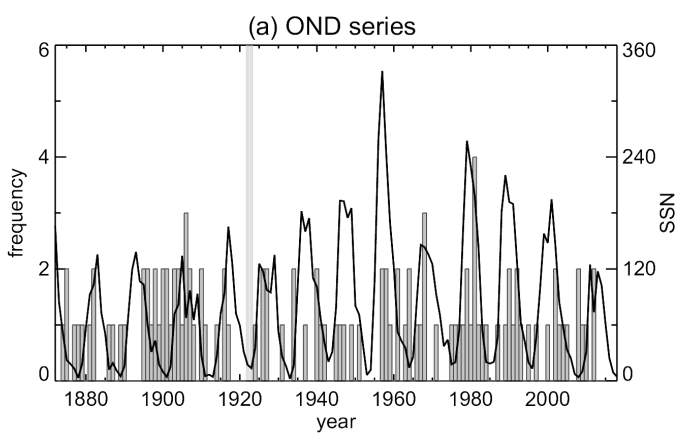

(b) OND events vs. SSN lag 1

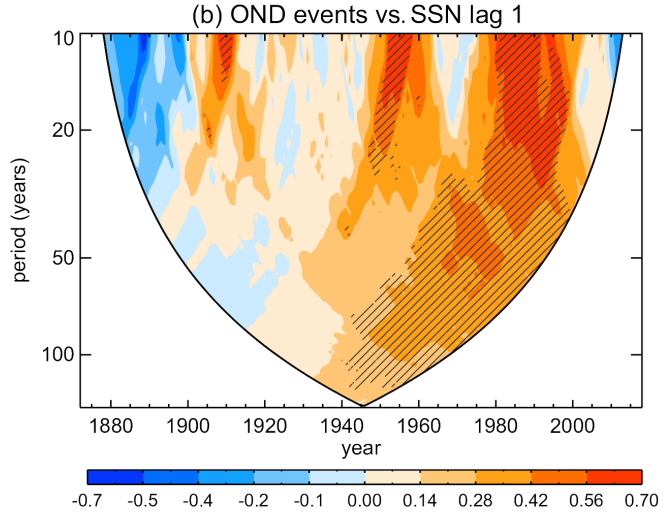

Figure 9. (a) Time series of the autumn frequency of independent daily mean detrended water height (IDMWH) extremes for 18722018 , defined as daily peaks above the 99.5 th percentile $(35.0 \mathrm{~cm})$ of the total distribution for the period 1924-2018. Daily peaks are required to be separated by more than $72 \mathrm{~h}$. The black line shows the autumn mean time series of the sunspot number (SSN). Bottom panel: rank Spearman's $(r)$ correlations between the autumn frequency of independent daily mean detrended water height extremes and the SSN for running windows of different width ( $y$ axis) centred at each year of the 1872-2018 period ( $x$ axis). Hatching denotes statistically significant correlations $(p<0.05)$. Correlations are only computed when the sample size is equal to or larger than 10, and it exceeds the half size of the window. Panel (b) shows the correlation pattern for SSN leading by 1 year, which produces the largest values. Data sources: World Data Center Sunspot Index and Long-term Solar Observations (WDC-SILSO), Royal Observatory of Belgium, Brussels (see Clette et al., 2014), and Raicich (2015). This figure follows the same approach adopted in Barriopedro et al. (2010), which considered the much shorter 1948-2008 period and the frequency of meteorological surge extremes.

1200 to 1740 the flood frequency was $<0.1$ per year, except for the Spörer period (1500-1540), when it was 0.63 per year. Subsequently, the frequency increased from 0.19 per year in 1830-1930 to 1.97 per year in 1965-2000. Considering specific thresholds, the number of floods above the $120 \mathrm{~cm}$ threshold has increased from 1.6 per decade (average frequency during the first half of the 20th century) to 40 per decade in the last decade (2010-2019). Considering a lower $(110 \mathrm{~cm})$ threshold, the number of events has increased from 4.2 to 95 per decade.
Former studies of recent trends (Trigo and Davies, 2002) found that in the second half of the 20th century the local RSL rise compensated for the decreasing frequency of storms, leading to no change in the frequency of floods. Other studies found a significant positive trend of moderate floods in Venice and Trieste during the second half of the 20th century (1951-1996) that was attributed to increases in the frequency of sirocco wind conditions over the central and southern Adriatic (Pirazzoli and Tomasin, 2002). A more recent study considered data in the period 1940-2007, reporting a $4 \%$ reduction in all water height events but no significant increase in the frequency or intensity of the most extreme events if the effect of RSL rise is subtracted from the data (Lionello et al., 2012b). According to Ferrarin et al. (2015), the detected increase in amplitude of the tidal waves enhanced the occurrence of severe water heights in Venice in the period 1940-2014, while changes in storminess had no significant long-term impact.

Observations made in Venice and Chioggia allowed the series of water height data to be extended back to the second half of the 18th century (Raicich, 2015). For this longer period, the time series of meteorological surge frequency does not exhibit a significant long-term trend but strong interannual and inter-decadal variability. In summary, the amount of current evidence shows that while the frequency of floods has clearly progressively increased in time after the mid20th century, there is no clear indication of a sustained trend at multi-decadal timescales in either the frequency or the severity of extreme meteorological surges. The presence of a substantial inter-annual and inter-decadal variability explains differences among studies which have considered different periods and different thresholds. The long-term increase in flood frequency is largely caused by RSL rise connected to both climatic change and land subsidence (see Zanchettin et al., 2021, in this special issue).

\subsection{Future evolution of extreme water heights}

Several past studies considered the future evolution of meteorological surges and water heights in the Adriatic Sea. A first analysis was based on a doubled- $\mathrm{CO}_{2}$ scenario and a single climate simulation (Lionello et al., 2003). Successive studies adopted the Special Report on Emissions Scenarios (SRES) and multiple simulations (Marcos et al., 2011; Lionello et al., 2012c; Troccoli et al., 2012; Mel et al., 2013). The most recent studies have considered the whole Mediterranean Sea or large parts of it and an ensemble of simulations for high- (RCP8.5) and moderate-emission (RCP4.5) scenarios (Conte and Lionello, 2013; Androulidakis et al., 2015; Vousdoukas et al., 2016; Lionello et al., 2017; Mentaschi et al., 2017; Vousdoukas et al., 2017, 2018). These studies are not fully comparable in that some of them (e.g Lionello et al., 2017) considered separated contributions from RSL rise and changes in meteorological surges, whereas others (e.g. Vousdoukas et al., 2017, 2018) addressed the overall change in 
sea level extremes. Further, Vousdoukas et al. (2017) considered the 100-year return values, while Lionello et al. (2017) considered annual maxima and 5- and 50-year return values. Studies assessing only meteorological surges suggest nonsignificant changes or a significant reduction in their intensity, which might reach about $5 \%$ for high emissions at the end of the 21st century (with consistent attenuation also of the wind wave height). This weak climate change signal is consistent with the future prevalent decrease in cyclone intensity and related wind speeds in the Mediterranean region that is suggested by most studies in spite of model-related uncertainty and subregional differences (see Reale et al, 2021, for a recent comprehensive update and Lionello et al., 2008; Zappa et al., 2013; Nissen et al., 2014; Zappa et al., 2015). However, there is substantial agreement that the future RSL rise will be the dominant factor that will increase frequency and height of floods (Lionello et al., 2017; Jackson and Jevrejeva, 2016; Jevrejeva et al., 2016; Vousdoukas et al., 2017, 2018). Only a very low rate of future RSL rise, such as that hypothesized in Troccoli et al. (2012), might prevent future increase in floods. However, such a low future RSL rise is very unlikely (Jordà et al., 2012) because it is lower than the global sea level rise under the RCP2.6 scenario in the Intergovernmental Panel on Climate Change (IPCC) Special Report on the Ocean and Cryosphere in a Changing Climate (SROCC) (Oppenheimer et al., 2019), and it would require the RSL rise in Venice during the 21st century to be lower than observed during the 20th century (see also Zanchettin et al., 2021, in this issue).

The future variation in amplitude of tides and surges in response to sea level rise will depend on the adaptation strategy of coastal defences (Bamber and Aspinall, 2013) - protection versus retreat. Lionello et al. (2005) showed that a full compensation strategy (protection), preserving the present coastline by dams, would reduce the amplitude of tides and storm surges, while a no compensation strategy, allowing permanent flooding of the low coastal areas (retreat), would increase the amplitude of the diurnal components and the amplitude of storm surges at the northern Adriatic coast. These effects are small but not negligible, being about $10 \%$ for the diurnal component in the case of $1 \mathrm{~m}$ sea level rise.

Projections of extreme sea levels (ESLs) were produced combining dynamic simulations of all relevant components during the present century and under moderate- and highemission scenarios. They include MSL rise and variations in future tides, meteorological surges, and wind wave set-up (Vousdoukas et al., 2017; Mentaschi et al., 2017; Vousdoukas et al., 2018) but do not include the effect of local subsidence. ESLs were produced through a probabilistic processbased framework (Jackson and Jevrejeva, 2016; Jevrejeva et al., 2016), incorporating the large uncertainties originating from the Greenland and Antarctic ice sheets under a highemission scenario (Bamber and Aspinall, 2013). Values for different return periods were estimated using non-stationary extreme value statistical analysis (Mentaschi et al., 2016) and

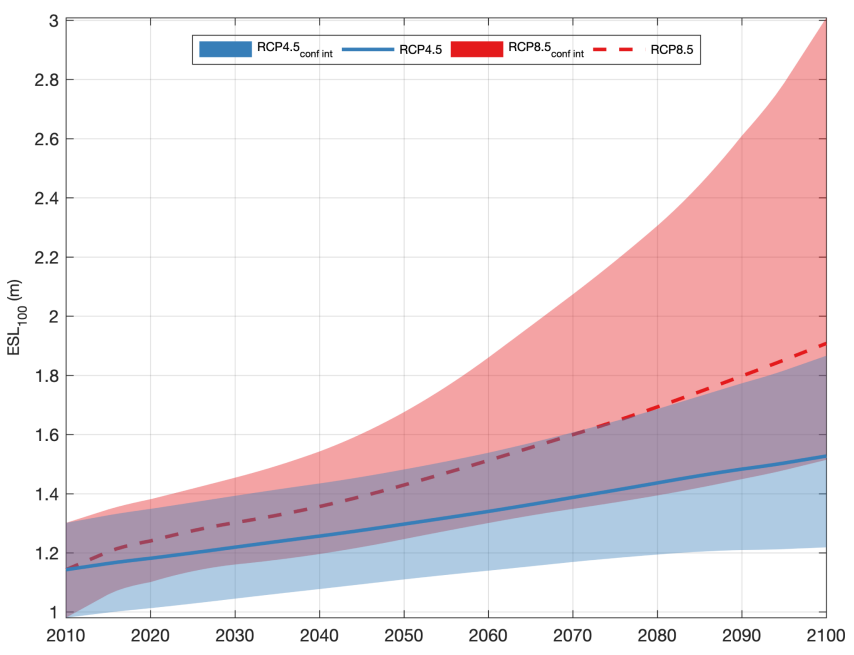

Figure 10. Time evolution of the 100-year ESL in the north-western Adriatic Sea under RCP4.5 (blue) and RCP8.5 (red). Lines show the corresponding medians, and coloured areas express the 5th-95th percentiles (very likely range). This figure follows the same graphic format, and it is based on the same simulations shown in Vousdoukas et al. (2017), but it specifically refers to the area marked with the red box in Fig. 1a.

variations with respect to the 2001-2020 baseline. Here, the spatially averaged values along the north-western Adriatic coast ${ }^{4}$ are considered.

The 100-year extreme sea level (100-year ESL) (Fig. 10) in the north-western Adriatic Sea by 2050 is very likely (595th percentile) to rise by 12 to $17 \mathrm{~cm}$ under the RCP4.5 moderate-emission-mitigation-policy scenario and by 26 to $35 \mathrm{~cm}$ under the RCP8.5 high-emission scenario (Vousdoukas et al., 2018). Similarly, it is very likely to rise by 24 56 and $53-171 \mathrm{~cm}$, respectively, by the end of the century. By the year 2050, the frequency of present-day 100-year events is projected to increase by 2 or 10 times (i.e. one event per 50 or 10 years) depending on the emission scenario. By the end of this century, events with the severity of current 1-in-100year extremes would occur at least every 5 years and 1 year under moderate and high emissions, respectively.

Breaking down the contributing factors to the increase in 100-year ESLs in the north-western Adriatic Sea (Fig. 11), thermal expansion accounts for $58 \%$ and $32 \%$ (median values) of the projected increase towards the end of the century under moderate and high emissions, respectively, while the Antarctica and Greenland ice sheet melting contributions vary from $14 \%$ to $20 \%$ (median values). However, the combined contributions from ice mass loss from glaciers and ice sheets in Greenland and Antarctica together are the dominant factor by 2100 , contributing $61 \%$ and $51 \%$ (median values) of the 100-year ESL increase under moderate and high emissions, respectively.

\footnotetext{
${ }^{4}$ The area in the red box in Fig. 1 is from 12.1 to $12.9^{\circ} \mathrm{W}$ and from 43.8 to $45.8^{\circ} \mathrm{N}$.
} 

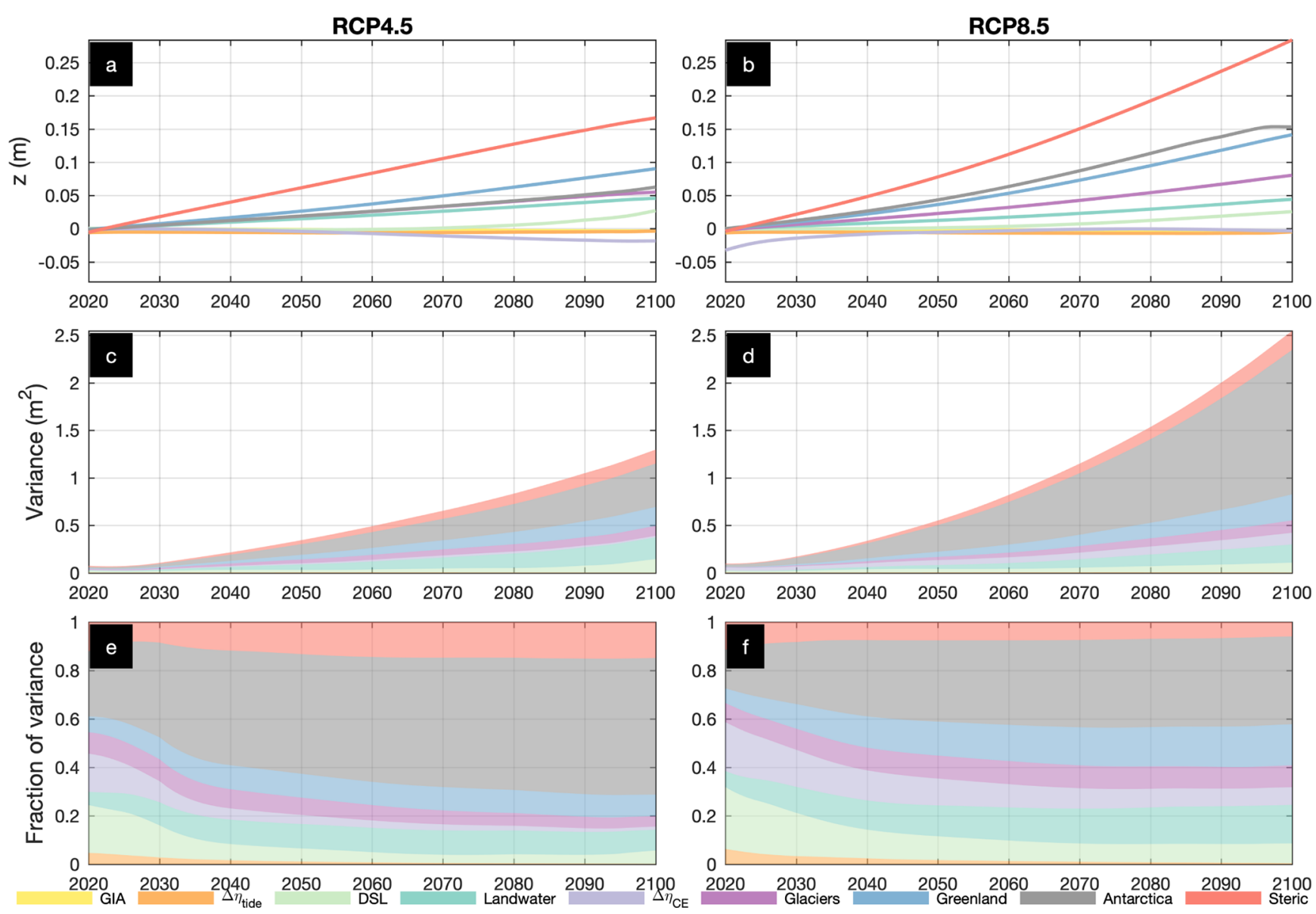

Figure 11. Breakdown of projected 100-year ESL contributions in the north-western Adriatic Sea and of their uncertainty under RCP4.5 (a, c, e) and RCP8.5 (b, d, f). Projected increase in the 100-year ESL (with respect to the 2001-2020 baseline) from changes in climate extremes and the high-tide water level as well as MSL rise contributions from Antarctica, land water, Greenland, glaciers, dynamic sea level (DSL), glacial isostatic adjustment (GIA), and steric effects (a, b); variance (in square metres) in components (c, d) and fraction of components' variance in global 100-year ESL change. Colours represent different components as in the legend, and values express the median. This figure follows the same graphic format, and it is based on the same simulations shown in Vousdoukas et al. (2018), but it specifically refers to the area marked with the red box in Fig. 1a.

While the above paragraphs discuss changes due to climatic and meteorological factors, the future dynamics of tides and surges in response to sea level rise will also depend on the evolution of the shoreline in the area. As sea levels rise, societies will have to decide whether to protect the coast and maintain the current shoreline (e.g. with coastal dams) or allow shoreline retreat. Previous studies (Lionello et al., 2005) have shown that a protection strategy would reduce the amplitude of tides and storm surges and increase that of Adriatic Sea seiches, while allowing for permanent flooding of the low coastal areas and retreat would increase the amplitude of the diurnal tide components and storm surges. These effects are small but not negligible, being about $10 \%$ for the diurnal component in the case of $1 \mathrm{~m}$ RSL rise.

\section{Conclusions and outlook}

There is a widespread view that the floods of the Venice city centre are mostly caused by storm surges and that the actual maximum water height depends substantially on the timing of the storm surge peak with respect to the phase of the astronomical tide. Consequently, efforts have traditionally focused on the correct simulation of the intensity, timing, and spatial variability in the wind (mainly the sirocco) for the accurate reproduction of water height extremes. This review confirms the paramount importance of storm surge, which produced the highest recorded flood (4 November 1966) but also identifies other phenomena that, though they individually produce lower water height anomalies than storm surge, can act constructively and yield extreme events. The event of 12 November 2019 (the second-highest flood ever recorded) provides a good example. Therefore, research is required on 
PAW surges and meteotsunamis, the other contributions to meteorological surges, including their joint distributions, in order to better understand the likelihood of compound events as that of November 2019. Furthermore, a multivariate statistical model that describes extreme water heights as a function of the various contributions would provide a more complete characterization of extreme events.

The actual effect of wave set-up on the water height inside the Venice lagoon remains uncertain. Some studies have computed it during individual storms affecting Venice (Bertotti and Cavaleri, 1985; Lionello, 1995; De Zolt et al., 2006) and for 100-year ESL projections (Vousdoukas et al., 2016, 2017) and have shown that the wave set-up contribution at the Adriatic shoreline can exceed $10 \mathrm{~cm}$, but its relevance for the flooding of Venice city centre would require it to initiate sufficiently offshore to affect the sea level at the lagoon inlets. This remains to be investigated.

The occurrence of floods, beside long-term RSL rise, is modulated by IDAS. Similarly, also the occurrence of meteorological surges displays strong inter-annual to decadal variability. Evidence linking this variability with astronomical (e.g. the solar cycle) and climate patterns (e.g. Northern Hemisphere teleconnections) remains elusive from both statistical and theoretical approaches. These issues are important for the development of seasonal predictions of sea level extremes and understanding of observed trends and their attribution to long-term anthropogenic climate change (and local subsidence). Longer records and better understanding of the sea level responses to atmospheric forcing and remote influences would contribute to fill these knowledge gaps.

The synoptic conditions leading to extreme storm surges at Venice are clearly documented as they are produced by cyclogenesis occurring in the western Mediterranean Sea. There is consensus on the secondary role that the meteorological forcing plays in the long-term changes in major floods. Its contribution may decrease further in the future because of their projected attenuation. However, the confidence in future weakening depends on the capability of climate models to correctly reproduce the full set of meteorological contributions under climate change, including storm surges, meteotsunamis, and PAW surges. Literature on projections of PAW surges and meteotsunamis is presently unavailable, and progress on these factors is urgently required as their changes may have different signs and magnitude from those of storm surges. Therefore, while presently available studies agree on the future attenuation of meteorological surges, analyses understanding the role of the different meteorological forcings in extreme sea level events are missing and deserve investigation.

This review confirms the consensus concerning the key control of the frequency and severity of floods in Venice exerted by historic and future RSL rise. Hence, understanding and predicting the future evolution of extreme water heights in Venice depend critically on the availability of RSL rise projections with lower uncertainty than at present. A large fraction of such uncertainty is related to the future emission scenario. Adopting a moderate-emission-mitigation-policy scenario (RCP2.6) or a high-emission scenario (RCP8.5) would imply a $30 \%$ difference in the projected 100 -year ESL at the end of the 21 st century. Another major source of uncertainty concerns the melting of ice sheets, which accounts for the largest increase in the 100-year ESL at the end of this century, particularly for a high-emission scenario. Further, scenarios for local anthropogenic and long-term natural subsidence need to be developed as they can further contribute to the future increase in extreme water heights. Other factors, such as changes in storminess or the deviation of the Mediterranean mean sea level from that of the subpolar North Atlantic (caused by steric effects and redistribution of mass within the Mediterranean Sea), appear to be less important (see Zanchettin et al., 2021, in this special issue).

Reducing uncertainty in the future projections of water height extremes is only one aspect of the research needed. The other aspect is adaptive planning of coastal defences to consider the large uncertainty in future evolution. A moderate scenario suggests a $10 \%$ and $30 \%$ increase in 100-year ESL in 2050 and 2100, respectively. A high-emission scenario shows a $25 \%$ increase already in 2050, reaching $65 \%$ in 2100 . These ranges are further enlarged by the uncertainty in scenario projections (leading to a 100 -year ESL increase of up to $65 \%$ and $160 \%$ in 2050 and 2100 , respectively), which should be further expanded to higher values including high-end scenarios (see Zanchettin et al., 2021, in this issue). Further, the inclusion of uncertainties in future subsidence is required to assess the likely range of future extreme water heights, which provide the actual information for the hazard to be faced by coastal defences and the environment of the city and of the lagoon. In other words, the uncertainty range in extreme water heights is larger than in ESLs and should be detailed at a finer spatial scale. The large range of possible changes, especially after 2050, is not expected to be reduced substantially in the upcoming years as it largely relies on human decisions and pervasive modelling uncertainties, which limits the generation of constrained climate information and poses major challenges for policy-making decisions on the development of effective adaptation measurements. These results (see also Lionello et al., 2020, in this special issue) stress the need for planning and implementing defence strategies of Venice that can be adapted to face the large range of plausible future sea level extremes. 


\section{Appendix A: Selected major events}

Here we present a short description of extreme sea level events based on original reports. Each description is based on the cited sources, which often include synoptic weather maps and diagrams of relevant meteorological parameters (see Table A1)

\section{A1 15 January 1867}

On 15 January 1867, that is just a few years before the beginning of regular sea level records, a remarkable storm surge occurred. Although no tide gauge data are available, contemporary sources reported measurements taken at local hydrometers.

Zantedeschi (1866-67), quoting the local civil engineering office (Ufficio del Genio Civile), reported that the maximum observed water height was $1.59 \mathrm{~m}$ "above the common ordinary high water marked at the royal hydrometer in the Grand Canal". The "common ordinary high water" is also known as the "comune marino" (CM), that is the upper edge of the green belt formed by algae on quays and walls, often indicated by an engraved horizontal mark and/or a "C" (Rusconi, 1983; Camuffo and Sturaro, 2004). According to Dorigo (1961a) the ZMPS is $22.46 \mathrm{~cm}$ below the CM of 1825 , upon which the tide gauge zero at S. Stefano was based. Therefore, under the hypothesis that the same CM was adopted at the royal hydrometer and at S. Stefano, the maximum water height should have been approximately $181 \mathrm{~cm}$ above the ZMPS.

However, later sources gave different values. Annali (1941) reported $132 \mathrm{~cm}$ above the $1825 \mathrm{CM}$; therefore the height would turn out to be $154 \mathrm{~cm}$ (153 is reported, maybe due to rounding). Dorigo (1961b) also reported $153 \mathrm{~cm}$, probably quoting Annali (1941).

If the $181 \mathrm{~cm}$ height was correct, the 1867 height would be the third-largest water height ever measured in Venice, not too far from the $187 \mathrm{~cm}$ of 12 November 2019 and the $194 \mathrm{~cm}$ reached on 4 November 1966. Note, however, that in the 1860 s the relative MSL was about $30 \mathrm{~cm}$ lower than at present, which makes the 1867 event very remarkable.

\section{A2 16 April 1936}

A cyclone affected the western and central Mediterranean, with a minimum MSLP around $990 \mathrm{hPa}$ in the Gulf of Lions, causing strong southerly winds to blow over the Adriatic. In Venice wind mostly blew from the first quadrant, but it veered to the south-south-west near the surge peak, with a gust speed over $25 \mathrm{~m} \mathrm{~s}^{-1}$; in the meantime the MSLP dropped to $990 \mathrm{hPa}$.

The water height reached $147 \mathrm{~cm}$; at that time it represented the second-highest value ever recorded, the first having been observed on 15 January 1867 (see above). The water height peak occurred about $2 \mathrm{~h}$ after the astronomical tide
Table A1. List of the events higher than $100 \mathrm{~cm}$ alongside the respective water height maxima. AN41: Annali, 1941; CA01: Canestrelli et al., 2001; CA19: Cavaleri et al., 2019; CA20: Cavaleri et al., 2020; CPSM: CPSM, 2019; DE06: de Zolt et al., 2006; DO61: Dorigo, 1961b; DO68: Dorigo, 1968; ISPRA: ISPRA, 2008-2018; ISP19: ISPRA-2019; ISP20: ISPRA, CPSM and CNR-ISMAR (2020).

\begin{tabular}{lrl}
\hline $\begin{array}{l}\text { Date } \\
\text { (yyyy-mm-dd) }\end{array}$ & $\begin{array}{r}\text { Max water height } \\
(\mathrm{cm})\end{array}$ & Sources \\
\hline $1966-11-04$ & 194 & DO68, CA01, BC06, CPSM \\
$2019-11-12^{*}$ & 189 & ISP20 \\
$1979-12-22$ & 166 & CA01, BC06, CPSM \\
$1986-02-01$ & 159 & CA01, BC06, CPSM \\
$2018-10-29^{*}$ & 156 & BC06, ISPRA, CPSM \\
$2008-12-01$ & 156 & BC06, ISPRA, CPSM \\
$2019-11-15$ & 154 & CPSM \\
$1951-11-12$ & 151 & DO61, CA01, BC06, CPSM \\
$2019-11-17$ & 150 & CPSM \\
$2012-11-11$ & 149 & BC06, ISPRA, CPSM \\
$2018-10-29 *$ & 148 & BC06, ISPRA, CPSM \\
$2002-11-16$ & 147 & BC06, CPSM \\
$1936-04-16$ & 147 & DO61, BC06, CPSM \\
$2009-12-25$ & 145 & BC06, CPSM \\
$1960-10-15$ & 145 & DO61, CA01, BC06, CPSM \\
$2019-12-23$ & 144 & ISP19 \\
$2019-11-13^{*}$ & 144 & CPSM \\
$2010-12-24$ & 144 & BC06, ISPRA, CPSM \\
$2009-12-23$ & 144 & BC06, CPSM \\
$2000-11-06$ & 144 & CA01, BC06, CPSM \\
$1968-11-03$ & 144 & CA01, BC06, CPSM \\
$2013-02-12$ & 143 & BC06, ISPRA, CPSM \\
$2012-11-01$ & 143 & BC06, ISPRA \\
$1992-12-08$ & 142 & CA01, BC06, CPSM \\
$1979-02-17$ & 140 & ISP20 \\
\hline
\end{tabular}

* Two water height peaks during the same event.

maximum. The meteorological surge contribution was about $91 \mathrm{~cm}$.

\section{A3 12 November 1951}

From 10 to 12 November 1951 a deep cyclone formed in the Ligurian Sea, where MSLP dropped from 1008 to $984 \mathrm{hPa}$. In the Ionian Sea and the Balkans MSLP was higher than 1012 $\mathrm{hPa}$, and the strong MSLP gradient induced strong southerly winds over the Adriatic Sea, up to over $20 \mathrm{~m} \mathrm{~s}^{-1}$ in Venice. As a result, the water height in Venice increased because of both the wind-induced surge and the local inverse barometer effect. Luckily, the surge peak occurred at the astronomical tide minimum. If it had occurred at the next high tide, $5 \mathrm{~h}$ later, the observed water height would have been about $65 \mathrm{~cm}$ higher. The water height peak was $151 \mathrm{~cm}$, and it exceeded the official danger level of $110 \mathrm{~cm}$ for about $9 \mathrm{~h}$. The meteorological surge peak attained $86 \mathrm{~cm}$. 


\section{A4 4 November 1966}

On 3 and 4 November 1966 the MSLP field over the Mediterranean was characterized by a cyclone to the west and an anticyclone to the east. The cyclone centre deepened and slowly moved from the north-western Mediterranean to north-eastern Italy, while the zonal MSLP gradient increased over the Adriatic. As a consequence, strong and persisting southerly wind affected the Adriatic Sea. In Venice, the sirocco speed reached $20 \mathrm{~m} \mathrm{~s}^{-1}$, with gusts up to $28 \mathrm{~m} \mathrm{~s}^{-1}$, and the MSLP dropped to $992 \mathrm{hPa}$.

The water height of $194 \mathrm{~cm}$ and the meteorological surge height of $143 \mathrm{~cm}$ are the highest values in the whole instrumental record. The water height remained over $110 \mathrm{~cm}$ for $22 \mathrm{~h}$. Economic losses for the city of about EUR 400 million have been estimated.

Note that two elements limited the water height peak, namely the fact that the astronomical tide was negative, though near zero, at the time of the maximum surge and that in those days the moon phase was close to the last quarter, making the astronomical tide amplitude relatively small, around $30 \mathrm{~cm}$. Had the surge peak occurred $5 \mathrm{~h}$ earlier, the water height would have attained about $220 \mathrm{~cm}$.

\section{A5 22 December 1979}

This event was connected with a cyclone whose minimum was less than $990 \mathrm{hPa}$ that moved on 21 and 22 December 1979 from the Algerian coast to the Gulf of Genoa. The combination with higher MSLP over the Balkans enabled southerly wind to blow over the central and southern Adriatic, with gusts up to $20 \mathrm{~m} \mathrm{~s}^{-1}$, while in the northern Adriatic, bora prevailed with gusts over $20 \mathrm{~m} \mathrm{~s}^{-1}$. The local MSLP was not particularly low $(1001 \mathrm{hPa})$; thus the surge was almost entirely attributed to wind.

The meteorological surge peak reached $106 \mathrm{~cm}$ and came $3 \mathrm{~h}$ before the astronomical tide maximum: nevertheless, the water height was remarkably high, namely $166 \mathrm{~cm}$, which represents the third-highest observed value. A water height higher than $110 \mathrm{~cm}$ lasted for $7 \mathrm{~h}$.

\section{A6 1 February 1986}

The synoptic situation consisted of a cyclone over the western Mediterranean, this time centred in the Gulf of Lions and an anticyclone over eastern and northern Europe. A southerly wind flow affected the whole central Mediterranean, including the Adriatic Sea, but a bora component was present over the northern Adriatic. Southerly wind was particularly strong in the southern Adriatic (almost $30 \mathrm{~m} \mathrm{~s}^{-1}$ gusts in Bari), while in Venice, bora gusts were faster than $20 \mathrm{~m} \mathrm{~s}^{-1}$.

This event is characterized by the fourth-highest water height ever measured in Venice, that is $159 \mathrm{~cm}$. The event severity was the result of a moderate meteorological surge of
$70 \mathrm{~cm}$ that occurred just $1 \mathrm{~h}$ after a $35 \mathrm{~cm}$ astronomical tide maximum and close to the peak of a large seiche.

\section{A7 6 November 2000}

This event was caused by the combined effect of a large cyclone affecting the whole of western Europe and an anticyclone over eastern Europe. The lowest MSLP was observed in the English Channel, with values lower than $970 \mathrm{hPa}$. The eastward movement of the cyclone caused the whole Adriatic to experience a remarkable MSLP decrease in the $24 \mathrm{~h}$ preceding the surge, up to a $27 \mathrm{hPa}$ drop in Venice.

As on 1 February 1986, during this event the storm surge and the astronomical tide maximum almost coincided. The observed water height attained $144 \mathrm{~cm}$, and the surge grew up to $87 \mathrm{~cm}$. The water height remained above $100 \mathrm{~cm}$ for over $7 \mathrm{~h}$.

\section{A8 1 December 2008}

An intense cyclone with strong westerly flow affected the western Mediterranean Sea. The day before the flood a smallscale cyclonic circulation developed over the Gulf of Genoa and moved eastward into the Po River valley. This caused surface wind over the Tyrrhenian and Adriatic seas to veer from the west to the south-west, then to the south, intensifying in the meantime and reaching the maximum intensity in the early hours of 1 December 2008. In the afternoon, the cyclonic circulation began weakening, and the intensity of the associated wind in the Adriatic Sea progressively decreased.

From the late afternoon of 30 November to the early morning of 1 December 2008, MSLP in Venice dropped by about $13 \mathrm{hPa}$ in $9 \mathrm{~h}$, reaching $994 \mathrm{hPa}$. The wind veered from the north-north-east to south-east around 01:30 UTC, with speeds between 15 and $20 \mathrm{~m} \mathrm{~s}^{-1}$ for the following 7-8 $\mathrm{h}$.

The water height attained $156 \mathrm{~cm}$, that is the fifth-highest value since 1872 . The maximum meteorological surge height was $62 \mathrm{~cm}$, and it occurred less than $1 \mathrm{~h}$ before the astronomical tide maximum.

\section{A9 29 October 2018}

The event was caused by the combined action of a cyclone, centred between the Gulf of Lions and the Gulf of Genoa, whose minimum MSLP was lower than $985 \mathrm{hPa}$, and an anticyclone over north-eastern and eastern Europe. This configuration enabled strong sirocco along the Adriatic, with speed around $15 \mathrm{~m} \mathrm{~s}^{-1}$ and gusts up to $25 \mathrm{~m} \mathrm{~s}^{-1}$ from the late morning to the evening in Venice, where MSLP reached a minimum of $996 \mathrm{hPa}$.

The strength and persistence of southerly winds caused the meteorological surge to remain particularly high. The highest water height was reached at 13:40 UTC, with $156 \mathrm{~cm}$ (fifthhighest value in the history of the observations in Venice), a couple of hours later than the astronomical tide maximum, then the water height decreased to $119 \mathrm{~cm}$ at $16: 35 \mathrm{UTC}$ 
and rose again up to $148 \mathrm{~cm}$ at 19:25 UTC. The meteorological surge level peaked at $91 \mathrm{~cm}$ together with the maximum water height and rose to $117 \mathrm{~cm}$ at 19:20 UTC, in coincidence with the astronomical tide minimum. The $117 \mathrm{~cm}$ meteorological surge level represents the second-highest ever observed and the $119 \mathrm{~cm}$ value the highest minimum water height. Overall, the water height was higher than $120 \mathrm{~cm}$ for $14 \mathrm{~h}$, as on 4 November 1966.

\section{A10 12, 15, and 17 November 2019}

On 12 November 2019, an exceptional flood event took place in Venice, second only to the 4 November 1966 event. Moreover, with 15 water heights above $110 \mathrm{~cm}$ and 4 above $140 \mathrm{~cm}$, November 2019 was the worst month for flooding in Venice since the beginning of sea level records.

The extremely high sea level recorded in Venice was due to the combination of the following large-scale and local dynamics:

- the in-phase timing between the peak of the storm surge and an astronomical tide maximum;

- the PAW surge produced by a standing low pressure and wind systems over the Mediterranean Sea persisting for the whole month of November (which determined a high monthly mean sea level in the northern Adriatic Sea);

- the storm surge produced by a deep low-pressure system over the south-central Tyrrhenian Sea that generated south-easterly winds along the main axis of the Adriatic Sea;

- the meteotsunamis produced by a fast-moving mesoscale cyclone travelling in the north-westward direction along the Italian coast of the Adriatic Sea;

- a local set-up produced by very strong south-westerly winds over the Lagoon of Venice.

The MSLP minimum of the cyclone over the Tyrrhenian Sea was about $990 \mathrm{hPa}$. A small deep secondary MSLP minimum formed in the afternoon, reaching $988 \mathrm{hPa}$ at Venice around 21:00 UTC. Initially, moderate north-easterly wind was blowing over the northern Adriatic (about $10 \mathrm{~m} \mathrm{~s}^{-1}$ at Venice), but between 21:00 and 22:00 UTC it veered to the south and east, then to the south-west, and sustained wind reinforced up to $20 \mathrm{~m} \mathrm{~s}^{-1}$ at Tessera airport.
The highest water height was reached at 21:50 UTC, with $189 \mathrm{~cm}$, which represents the second-highest value in the history of the observations in Venice, and it almost exactly coincided with the astronomical tide peak. The meteorological surge level peaked at $100 \mathrm{~cm}$, representing the fourth-highest value ever observed. The peak water height was similar to the 1966 value (namely $194 \mathrm{~cm}$ ), but, while in 1966 it was mainly the result of a huge meteorological component $(143 \mathrm{~cm}$; see Sect. A4 above), in 2019 the astronomical tide contribution also played a significant role. Moreover, in 2019 the RSL was $11 \mathrm{~cm}$ higher with respect to 1966 .

On 15 November 2019 another storm surge developed in connection with a large cyclone over western Europe, having a $995 \mathrm{hPa}$ MSLP minimum over France and extending into Algeria. Local pressure in Venice reached $1001 \mathrm{hPa}$, and wind blew from the south-east at less than $10 \mathrm{~m} \mathrm{~s}^{-1}$. The water height peaked at $154 \mathrm{~cm}$ at 10:40 UTC.

\section{Appendix B: Simulation of the tide-meteorological surge interactions}

This short appendix is dedicated to an experiment carried out using the model framework of Cavaleri et al. (2019). Three different simulations have been performed using only the astronomical tidal forcing (SHYFEM Tide), the meteorological forcing (SHYFEM Surge), and the full forcing (SHYFEM Total). The difference between the "SHYFEM Total" simulation and the sum of "SHYFEM Surge" and "SHYFEM Tide" represents the effect of the non-linear interactions between the astronomical tide and the meteorological surge. Figure B1 shows the results of the simulation and the small magnitude of the non-linear effect, which is only about $5 \%$ of the total surge, in correspondence with the highest peak in the simulated period. 


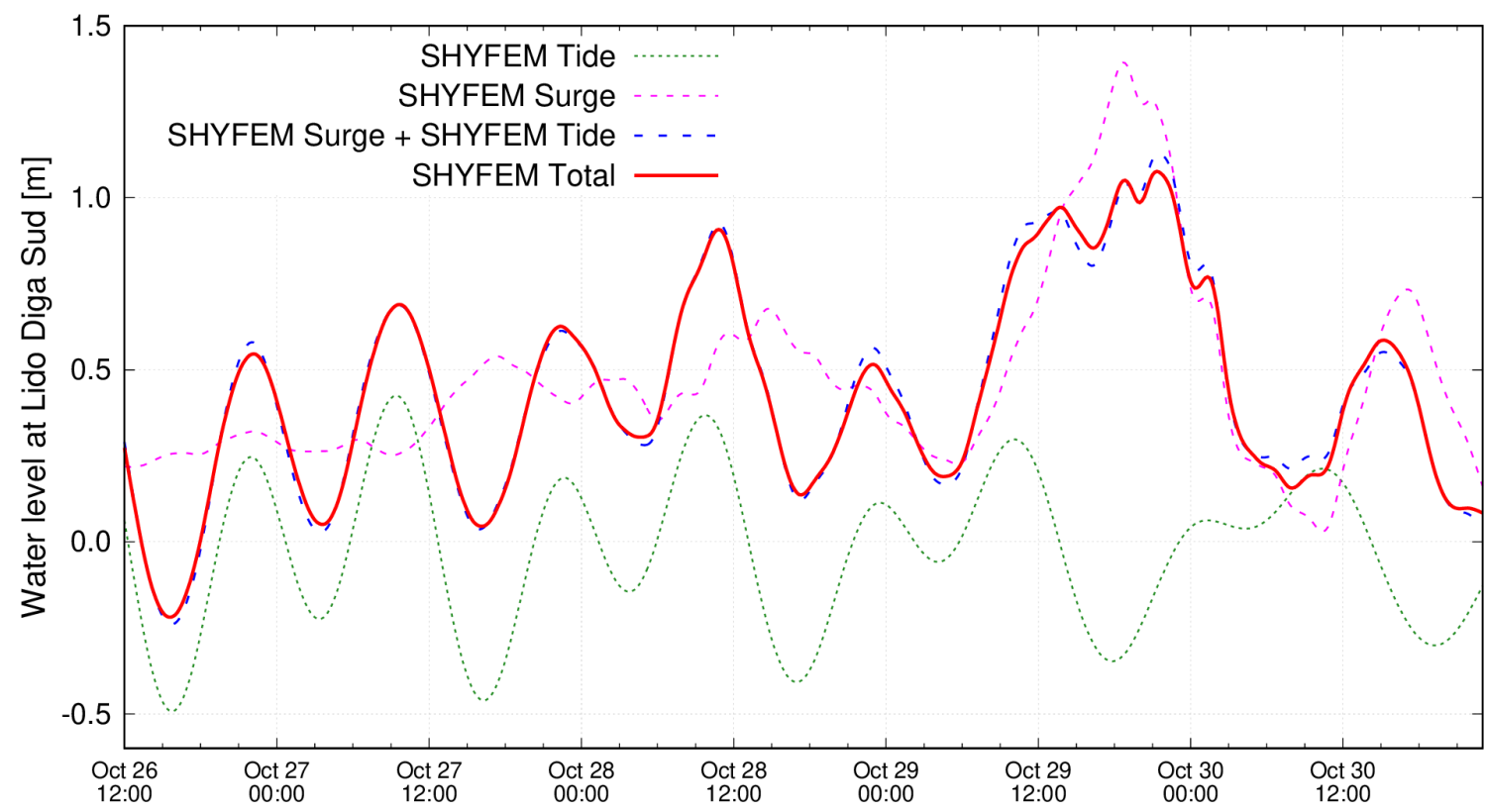

Figure B1. Simulation of the event A9 described in Appendix A performed with SHYFEM (Shallow water HYdrodynamic Finite Element Model; see Cavaleri et al., 2019, for details). The different curves represent the model results using only the astronomical tidal forcing (SHYFEM Tide), the meteorological forcing (SHYFEM Surge), and the full forcing (SHYFEM Total). The dashed line (SHYFEM Surge + SHYFEM Tide) is the algebraic sum of the SHYFEM Tide and SHYFEM Surge results.

\section{Appendix C: Wavelet of the storm surge frequency}

In order to integrate the discussion in Sect. 5.3 on the presence of an 11-year periodicity of extreme detrended water heights, Figs. $\mathrm{C} 1$ and $\mathrm{C} 2$ show the amplitude of the wavelets of the time series of the autumn mean water height for 19242018 and of its daily meteorological surge extremes. Missing values in the time series before 1924 prevented the computation of the wavelet transform in Fig. $\mathrm{C} 1$ for the whole period 1872-2018 covered by the data. Figure $\mathrm{C} 2$ has been limited to the same period for coherence with Fig. C1. In both graphics, a decadal signal consistent with the 11-year solar cycle is present only for a few decades, from the 1970s to the 1990s, and absent before and after this period. 


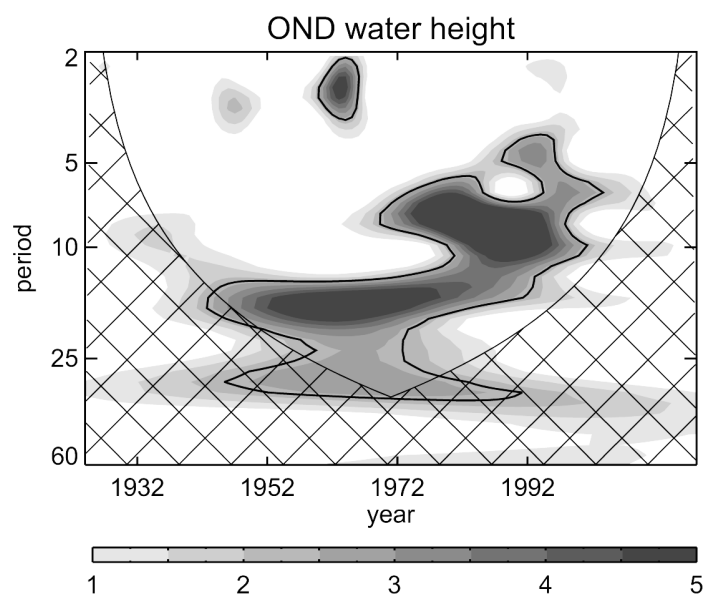

Figure C1. Wavelet of time series of the autumn (October-November-December) mean water height for 1924-2018, expressed as power values normalized by the variance. Seasonal values are obtained from monthly means of the daily series. Less than $10 \%$ of days are missing for all months of this period. Significant power density at $90 \%$ confidence level is highlighted by contours. This figure follows the same approach adopted in Barriopedro et al. (2010), which considered the much shorter 1948-2008 period.

(a) OND events 97.5

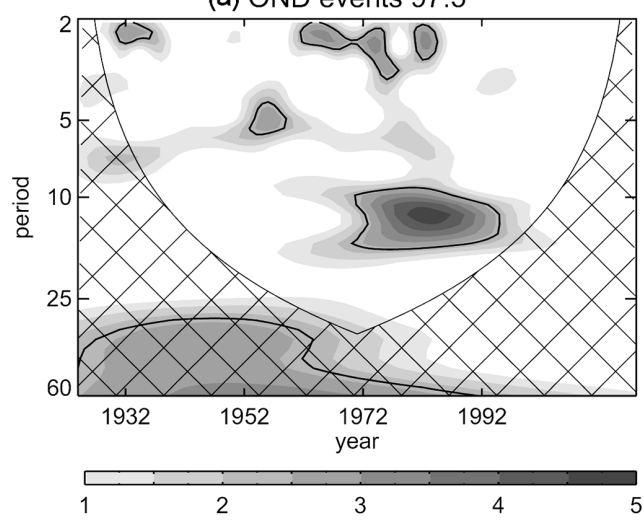

(c) OND events 99.5

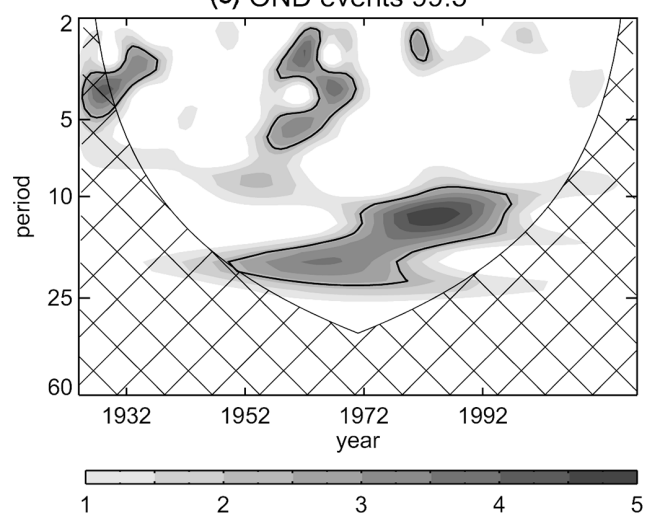

(b) OND events 99.0

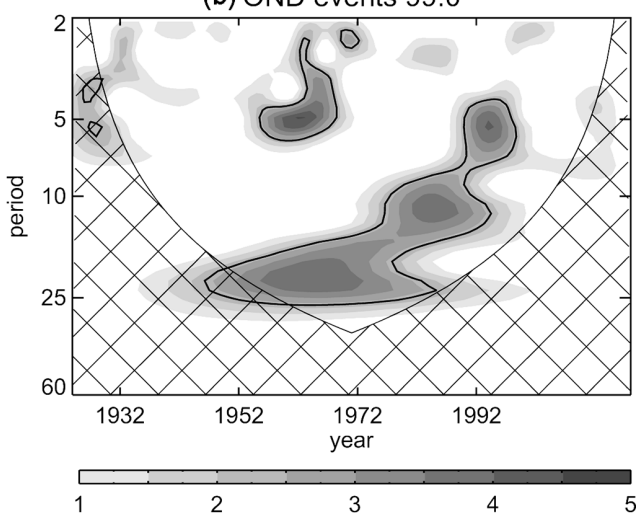

(d) OND events 99.9

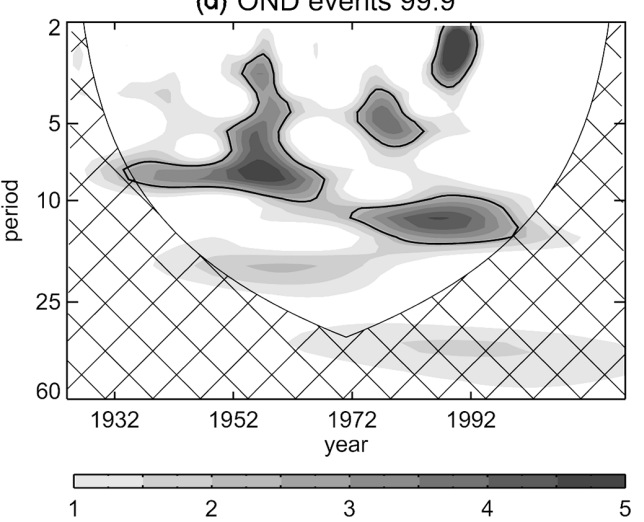

Figure C2. As Fig. A2 but for the autumn frequency series of daily detrended water heights above the 97.5th, 99th, 99.5th, and 99.9th percentiles. This figure follows the same approach adopted in Barriopedro et al. (2010), which considered the much shorter 1948-2008 period and hourly data. 
Data availability. ERA5 data used in Figs. 4, 5, and 6 are freely available at the Copernicus Climate Data Store (https://cds.climate.copernicus.eu/ (last access: 1 August 2021) (Copernicus Climate Data Store, 2021); see item ERA5 hourly data on single levels from 1979 to present). The NCEP/NCAR reanalysis data used in Figs. 7 and 8 are freely available at NOAA/PSL: https://psl.noaa.gov/data/gridded/data.ncep.reanalysis.html (last access: 1 August 2021) (NOAA, 2021). Weather regime classification is available upon request (contact: david.barriopedro@csic.es). Solar cycle data used in Fig. 9 are from the World Data Center - Sunspot Index and Long-term Solar Observations; data are available at https://wwwbis.sidc.be/silso/datafiles (last access: 1 August 2021) (Royal Observatory of Belgium, 2021) (contact Frédéric Clette; email: silso.info@oma.be). Daily average water height data for Fig. 9, C1, and C2 are available upon request (contact: fabio.raicich@ts.ismar.cnr.it). The data used in Figs. 10 and 11 are available at the links http: //data.europa.eu/89h/a565eea4-5422-4c7d-a000-2e10ae872da7 (last access: 1 August 2021) (JRC, 2021a) (extreme sea level - RCP85) and http://data.europa.eu/89h/ e9e42344-119d-479e-9bc7-57400d12a8a2 (extreme sea level - RCP45) (JRC, 2021a). A historical archive "acque alte eccezionali" of exceptional water heights in Venice is available at https://www.comune.venezia.it/content/le-acque-alte-eccezionali (last access: 1 August 2021) (Città di Venezia, 2020). Observed tide gauge data are available at the ISPRA website: https://www.venezia.isprambiente.it/index.php?folder_id=20\& stazione_id=129\&tipo_dati_id=1\&view=year (last access: 1 August 2021) (ISPRA, 2021).

Author contributions. PL coordinated the paper. PL was the leading author of Sect. 1, and RJN and DZ were contributing authors. MO and FR were the leading authors of Sect. 2, and PL, GU, and $\mathrm{CF}$ were contributing authors. MR and DB were the leading authors of Sect. 3, and FR and PL were contributing authors. MV was the leading author of Sect. 4, and FR and PL were contributing authors. PL was the leading author of Sect. 5, and RJN, DZ, and DB were contributing authors. MR produced Figures 1, 4, 5, and 6; PL produced Fig. 2; GU produced Fig. 3; DB produced Figs. 7, 8, and 9; MV produced Figs. 10 and 11; CF produced Table 1; FR produced Table 2; FR was the author of Appendix A and Table A1; CF was the author of Appendix B and Fig. B1; DB was the author of Appendix $\mathrm{C}$ and Figs. $\mathrm{C} 1$ and $\mathrm{C} 2$.

Competing interests. The authors declare that they have no conflict of interest.

Disclaimer. Publisher's note: Copernicus Publications remains neutral with regard to jurisdictional claims in published maps and institutional affiliations.

Special issue statement. This article is part of the special issue "Venice flooding: understanding, prediction capabilities, and future projections". It is not associated with a conference.
Acknowledgements. Scientific activity by Davide Zanchettin and Georg Umgiesser was performed in the research programme Venezia2021, with the contribution of the superintendency for the Public Works of Veneto, Trentino Alto Adige, and Friuli Venezia Giulia, provided through the concessionary of State Consorzio Venezia Nuova and coordinated by CORILA.

Financial support. Marco Reale has been supported in this work by the OGS and Cineca under HPC-TRES award number 201507 and by the project FAIRSEA (Fisheries in the Adriatic Region - a Shared Ecosystem Approach) funded by the 2014-2020 Interreg V-A Italy-Croatia CBC programme (standard project ID 10046951). The work of Mirko Orlić has been supported by the Croatian Science Foundation under the project IP-2018-01-9849 (MAUD). David Barriopedro was supported by the Spanish government through the PALEOSTRAT (CGL2015-69699-R) and JEDiS (RTI2018-096402-BI00) projects.

Review statement. This paper was edited by Uwe Ulbrich and reviewed by two anonymous referees.

\section{References}

Androulidakis, Y. S., Kombiadou, K. D., Makris, C. V., Baltikas, V. N., and Krestenitis, Y. N.: Storm surges in the Mediterranean Sea: Variability and trends under future climatic conditions, Dynam. Atmos. Oceans, 71, 56-82, 2015.

Annali: Annali Idrologici 1936, Elaborazioni e studi, Ufficio Idrografico del Magistrato alla Acque Venezia, Rome, Italy, 1941.

Arns, A., Wahl, T., Wolff, C., Vafeidis, A. T., Haigh, I. D., Woodworth, P., Niehüser, S., and Jensen, J..: Non-linear interaction modulates global extreme sea levels, coastal flood exposure, and impacts, Nat. Commun., 11, 1-9, 2020.

Bajo, M., Zampato, L., Umgiesser, G., Cucco, A., and Canestrelli, P.: A finite element operational model for storm surge prediction in Venice, Estuar. Coast. Shelf S., 75, 236-249, 2007.

Bajo, M., Međugorac, I., Umgiesser, G., and Orlić, M.: Storm surge and seiche modelling in the Adriatic Sea and the impact of data assimilation, Q. J. Roy. Meteor. Soc., 145, 2070-2084, 2019.

Bamber, J. L. and Aspinall, W. P.: An expert judgement assessment of future sea-level rise from the ice sheets, Nat. Clim. Change, 3, 424-427, 2013.

Bargagli, A., Carillo, A., Pisacane, G., Ruti, P. M., Struglia, M. V., and Tartaglione, N.: An Integrated Forecast System over the Mediterranean Basin: Extreme Surge Prediction in the Northern Adriatic Sea, Mon. Weather Rev., 130, 1317-1332, 2002.

Barriopedro, D., García-Herrera, R., Lionello, P.. and Pino, C.: A discussion of the links between solar variability and high-stormsurge events in Venice, J. Geophys. Res.-Atmos., 115, D13101, https://doi.org/10.1029/2009JD013114, 2010.

Battistin, D. and Canestrelli, P.:1872-2004 La serie storica delle maree a Venezia, Venice, Italy: Istituzione Centro Previsioni e Segnalazioni Maree. available at: https://www.comune.venezia. it/sites/default/files/publicCPSM2/pubblicazioni/La_serie_ storica_delle_maree_a_Venezia_1872-2004_web_ridotto.pdf (last access: 29 July 2021), 2006. 
Bertotti, L. and Cavaleri, L.: Coastal set-up and wave breaking, Oceanol. Acta, 8, 237-242, 1985.

Bertotti, L., Bidlot, J.-R., Buizza, R., Cavaleri, L., and Janousek, M.: Deterministic and ensemble-based prediction of Adriatic Sea sirocco storms leading to "acqua alta" in Venice, Q. J. Roy. Meteor. Soc., 137, 1446-1466, 2011.

Camuffo, D. and Sturaro, G.: Use of proxy-documentary and instrumental data to assess the risk factors leading to sea flooding in Venice, Global Planet. Change, 40, 93-103, 2004.

Canestrelli, P., Mandich, M., Pirazzoli, P. A., and Tomasin, A.: Wind, Depressions and Seiche: Tidal Perturbations in Venice (1951-2000), Venice, Italy: Istituzione Centro Previsioni e Segnalazioni Maree, available at: https://www.comune.venezia.it/sites/default/files/publicCPSM2/ pubblicazioni/Venti_depressioni_e_sesse.pdf (last access: 29 July 2021), 2001.

Caporin, M. and Fontini, F.: Damages Evaluation, Periodic Floods, and Local Sea Level Rise: The Case of Venice, Italy, Handbook of Environmental and Sustainable Finance, Academic Press, 93110, https://doi.org/10.1016/C2014-0-05175-1, 2016.

Cavaleri, L., Bertotti, L., Buizza, R., Buzzi, A., Masato, V., Umgiesser, G., and Zampieri, M.: Predictability of extreme meteo-oceanographic events in the Adriatic Sea, Q. J. Roy. Meteor. Soc., 136, 400-413, 2010.

Cavaleri, L., Bajo, M., Barbariol, F., Bastianini, M., Benetazzo, A.,Bertotti, L., Chiggiato, J., Davolio, S., Ferrarin, C., Magnusson, L., Papa, A., Pezzutto, P., Pomaro, A., and Umgiesser, G.: The October 29, 2018 storm in Northern Italy - an exceptional event and its modeling, Prog. Oceanogr., 178, 102178, https://doi.org/10.1016/j.pocean.2019.102178, 2019.

Cavaleri, L., Bajo, M., Barbariol, F., Bastianini, M., Benetazzo, A., Bertotti, L., Chiggiato, J., Ferrarin, C., Trincardi, F., and Umgiesser, G.: The 2019 flooding of Venice and its implications for future predictions, Oceanography, 33, 42-49, 2020.

Cerovečki, I., Orlić, M., and Hendershott, M. C.: Adriatic seiche decay and energy loss to the Mediterranean, Deep-Sea Res. Pt. I, 44, 2007-2029, 1997.

Chiodo, G., Oehrlein, J., Polvani, L. M., Fyfe, J. C., and Smith, A. K.: Insignificant influence of the 11-year solar cycle on the North Atlantic Oscillation, Nat. Geosci., 12, 94-99, 2019.

Città di Venezia: Acque alte eccezionali, [data set], available at: https://www.comune.venezia.it/content/ le-acque-alte-eccezionali, last access: 30 September 2020.

Clette, F., Svalgaard, L., Vaquero, J. M., and Cliver, E. W.: Revisiting the sunspot number, Space Sci. Rev., 186, 35-103, 2014.

Codiga, D. L.: Unified tidal analysis and prediction using the UTide Matlab functions. Graduate School of Oceanography, Technical Report, University of Rhode Island Narragansett, RI, 2011.

Conte, D. and Lionello, P.: Characteristics of large positive and negative surges in the Mediterranean Sea and their attenuation in future climate scenarios, Global Planet. Change, 111, 159-173, 2013.

Copernicus Climate Data Store: ERA5 hourly data on single levels from 1979 to present, available at: https://cds.climate.copernicus. eu/, last access: 1 August 2021.

CPSM: Istituzione Centro Previsioni e Segnalazioni Maree, Historical archive of tides in Venice 1983-2018, available at: https: //www.comune.venezia.it/content/le-acque-alte-eccezionali, last access: 4 August 2019.
De Zolt, S., Lionello, P., Nuhu, A., and Tomasin, A.: The disastrous storm of 4 November 1966 on Italy, Nat. Hazards Earth Syst. Sci., 6, 861-879, https://doi.org/10.5194/nhess-6861-2006, 2006.

Dorigo, L.: Le osservazioni mareografiche in Laguna di Venezia, Ist. Veneto Sc., Lett. Arti, Commissione di studio dei provvedimenti per la conservazione e difesa della Laguna e della città di Venezia, Rapporti preliminari, vol. I, 11-38, 1961a.

Dorigo, L.: Maree eccezionali registrate a Venezia Punta della Salute, Periodo 1867-1960, Ist. Veneto Sc., Lett. Arti, Commissione di studio dei provvedimenti per la conservazione e difesa della Laguna e della città di Venezia, Rapporti preliminari, vol. I, 39-69, 1961b.

Dorigo, L.: Le alte maree eccezionali a Venezia, Ufficio Idrografico del Magistrato alle Acque, Publ. N. 156, Venice, 1968.

Enzi, S. and Camuffo, D.: Documentary sources of the sea surges in Venice from ad 787 to 1867, Nat. Hazards, 12, 225-287, 1995.

Fagherazzi, S., Fosser, G., D’Alpaos, L., and D’Odorico, P.: Climatic oscillations influence the flooding of Venice, Geophys. Res. Lett., 32, L19710, https://doi.org/10.1029/2005GL023758, 2005.

Ferrarin, C., Tomasin, A., Bajo, M., Petrizzo, A., and Umgiesser, G.: Tidal changes in a heavily modified coastal wetland, Cont. Shelf Res., 101, 22-33, 2015.

Ferrarin, C., Maicu, F., and Umgiesser, G.: The effect of lagoons on Adriatic Sea tidal dynamics, Ocean Model., 119, 57-71, 2017.

Ferrarin, C., Bajo, M., Benetazzo, A., Cavaleri, L., Chiggiato, J., Davison, S., Davolio, S., Lionello, P. Orlić, M., and Umgiesser, G.: Local and large-scale controls of the exceptional Venice floods of November 2019, Prog. Oceanogr., 197, 102628, https://doi.org/10.1016/j.pocean.2021.102628, 2021.

Flaounas, E., Kelemen, F. D., Wernli, H., Gaertner, M. A., Reale, M., Sanchez-Gomez, E., Lionello, P., Calmanti, S., Podrascanin, Z., Somot, S., Akhtar, N., Romera, R., and Conte, D.: Assessment of an ensemble of ocean-atmosphere coupled and uncoupled regional climate models to reproduce the climatology of Mediterranean cyclones, Clim. Dynam., 51, 1023-1040, 2018.

Franco, P., jefti ć, L., Malanotte Rizzoli, P., Orlić, M., and Purga, N.: Descriptive Model of the Northern Adriatic, Oceanol. Acta, 5, 11 pp., 1982.

Garrido-Perez, J. M., Ordóñez, C., Barriopedro, D., García-Herrera, R., and Paredes, D.: Impact of weather regimes on wind power variability in western Europe, Appl. Energ., 264, 114731, 2020.

Godlewski, G., Caporalini, L., and Deuss, B.: "Acqua Alta" and the need for the Mo.S.E. project, TU Delft, student research project report, available at: http://resolver.tudelft.nl/uuid: ea34a719-79c1-4c6e-b886-e0d92407bc9d (last access: $1 \mathrm{Au}-$ gust 2021), 2020.

Gregory, J. M., Griffies, S. M., Hughes, C. W., Lowe, J. A., Church, J. A., Fukimori, I., Gomez, N., Kopp, R.E., Landerer, F., Le Cozannet, G., Ponte, R. M., Stammer, D., Tamisiea, M. E., and van de Wal, R. S.: Concepts and terminology for sea level: Mean, variability and change, both local and global, Surv. Geophys., 40, 1251-1289, 2019.

Hendershott, M. C. and Speranza, A.: Co-oscillating tides in long, narrow bays; the Taylor problem revisited, Deep-Sea Res. Oceanogr. Abstr, 18, 959-980, 1971.

Hersbach, H., Bell, B., Berrisford, P., Hirahara, S., Horányi, A., Muñoz-Sabater, J., Nicolas, J., Peubey, C., Radu, R., and Schep- 
ers, D.: The ERA5 global reanalysis, Q. J. Roy. Meteor. Soc., 146, 1999-2049, 2020.

Holton, J. R.: An Introduction to Dynamic Meteorology, Fourth Edition, Elsevier, Amsterdam, 535 pp., 2004.

Horsburgh, K. J. and Wilson, C.: Tide-surge interaction and its role in the distribution of surge residuals in the North Sea, J. Geophys. Res.-Oceans, 112, C08003, https://doi.org/10.1029/2006JC004033, 2007.

ISPRA: Rapporto 01-2008; Rapporto 05-2010; Rapporto 01-2012; Rapporto 01-2013; Rapporto 02-2018, available at: http://www. venezia.isprambiente.it/bollettino\#Analisieventidimarea (last access: 12 August 2019), 2008-2018.

ISPRA - Istituto Superiore per la Protezione e la Ricerca Ambientale: Punta della Salute tide gauge data, [data set], available at: https://www.venezia.isprambiente.it/index.php?folder_ id=20\&stazione_id=129\&tipo_dati_id=1\&view=year, last access: 1 August 2021.

ISPRA, CPSM and CNR-ISMAR: Un mese di alte maree eccezionali. Dinamica e anomalia dell'evento del 12 novembre 2019, available at: https://www.comune.venezia.it/content/ le-acque-alte-eccezionali, last access: 30 September 2020.

Jackson, L. P. and Jevrejeva, S.: A probabilistic approach to 21st century regional sea-level projections using RCP and High-end scenarios, Global Planet. Change, 146, 179-189, 2016.

Janeković, I. and Kuzmić, M.: Numerical simulation of the Adriatic Sea principal tidal constituents, Ann. Geophys., 23, 3207-3218, https://doi.org/10.5194/angeo-23-3207-2005, 2005.

Jansa, A., Alpert, P., Arbogast, P., Buzzi, A., Ivancan-Picek, B., Kotroni, V., Llasat, M. C., Ramis, C., Richard, E., Romero, R., and Speranza, A.: MEDEX: a general overview, Nat. Hazards Earth Syst. Sci., 14, 1965-1984, https://doi.org/10.5194/nhess14-1965-2014, 2014.

Jevrejeva, S., Jackson, L. P., Riva, R. E. M., Grinsted, A., and Moore, J. C.:Coastal sea level rise with warming above $2{ }^{\circ} \mathrm{C}, \mathrm{P}$. Natl. Acad. Sci. USA, 113, 13342-13347, 2016.

Jordà, G., Gomis, D., and Marcos, M.: Comment on "Storm surge frequency reduction in Venice under climate change" by Troccoli et al., Clim. Change, 113, 1081-1087, 2012.

JRC - Joint Research Centre: Extreme Sea level RCP45, [data set], available at: http://data.europa.eu/89h/ e9e42344-119d-479e-9bc7-57400d12a8a2 (last access: 1 August 2021), 2021a.

JRC - Joint Research Centre: Extreme Sea level RCP85, [data set], available at: http://data.europa.eu/89h/ a565eea4-5422-4c7d-a000-2e10ae872da7 (last access: 1 August 2021), 2021b.

Kalnay, E., Kanamitsu, M., Kistler, R., Collins, W., Deaven, D., Gandin, L., Iredell, M., Saha, S., White, G., Woollen, J., Zhu, Y., Leetmaa, A., Reynolds, B., Chelliah, M., Ebisuzaki, W., Higgins, W., Janowiak, J., Mo, K. C., Ropelewski, C., Wang, J., Jenne, R., and Joseph, D.: The NCEP/NCAR 40-Year Reanalysis Project, B. Am. Meteorol. Soc., 77, 437-472, 1996.

Lionello, P.: Oceanographic prediction for the Venetial Littoral, Nuovo Cimento C., 18, 245-268, 1995.

Lionello, P., Dalan, F., and Elvini, E.: Cyclones in the Mediterranean region: the present and the doubled $\mathrm{CO}_{2}$ climate scenarios, Clim. Res., 22, 147-159, 2002.

Lionello, P.: Extreme storm surges in the Gulf of Venice: Present and future climate, in Flooding and Environmental Challenges for Venice and Its Lagoon: State of Knowledge, edited by: Fletcher, C. A. and Spencer, T., 59-69, Cambridge Univ. Press, New York, 0521840465, 2005

Lionello, P., Nizzero, A., and Elvini, E.: A procedure for estimating wind waves and storm-surge climate scenarios in a regional basin: The Adriatic Sea case, Clim. Res., 23, 217-231, 2003.

Lionello, P., Mufato, R., and Tomasin, A.: Sensitivity of free and forced oscillations of the Adriatic Sea to sea level rise, Clim. Res., 29, 23-39, 2005.

Lionello, P., Bhend, J., Buzzi, A., Della-Marta, P. M., Krichak, S. O., Jansa, A., Maheras, P., Sanna, A., Trigo, I. F., and Trigo, R.: Cyclones in the Mediterranean region: climatology and effects on the environment, Developments in earth and environmental sciences, Elsevier, 325-372, https://doi.org/10.1016/S15719197(06)80009-1, 2006a.

Lionello, P., Sanna, A., Elvini, E., and Mufato, R.: A data assimilation procedure for operational prediction of storm surge in the northern Adriatic Sea, Cont. Shelf Res., 26, 539-553, 2006b.

Lionello, P., Boldrin, U., and Giorgi, F.: Future changes in cyclone climatology over Europe as inferred from a regional climate simulation, Clim. Dynam., 30, 657-671, 2008.

Lionello, P., Abrantes, F., Congedi, L., Dulac, F., Gacic, M., Gomis, D., Goodess, C., Hoff, H., Kutiel, H., Luterbacher, J., Planton, S., Reale, M., Schröder, K., Vittoria Struglia, M., Toreti, A., Tsimplis, M., Ulbrich, U., and Xoplaki, E.: Introduction: Mediterranean Climate-Background Information, in: The Climate of the Mediterranean Region: From the Past to the Future, edited by: Lionello, P., Elsevier Inc., xxxv-xc, https://doi.org/10.1016/B978-0-12-416042-2.00012-4, 2012a.

Lionello, P., Cavaleri, L., Nissen, K. M., Pino, C., Raicich, F., and Ulbrich, U.: Severe marine storms in the Northern Adriatic: Characteristics and trends, Phys. Chem. Earth, 40-41, 93-105, 2012b.

Lionello, P., Galati, M. B., and Elvini, E.: Extreme storm surge and wind wave climate scenario simulations at the Venetian littoral, Phys. Chem. Earth, 40-41, 86-92, 2012c.

Lionello, P., Trigo, I. F., Gil, V., Liberato, M. L. R., Nissen, K. M., Pinto, J. G., Raible, C. C., Reale, M., Tanzarella, A., Trigo, R. M., Ulbrich, S., and Ulbrich, U.: Objective climatology of cyclones in the Mediterranean region: A consensus view among methods with different system identification and tracking criteria, Tellus A, 68, 29391, https://doi.org/10.3402/tellusa.v68.29391, 2016.

Lionello, P., Conte, D., Marzo, L., and Scarascia, L.: The contrasting effect of increasing mean sea level and decreasing storminess on the maximum water level during storms along the coast of the Mediterranean Sea in the mid 21st century, Global Planet. Change, 151, 80-91, 2017.

Lionello, P., Conte, D., and Reale, M.: The effect of cyclones crossing the Mediterranean region on sea level anomalies on the Mediterranean Sea coast, Nat. Hazards Earth Syst. Sci., 19, 1541-1564, https://doi.org/10.5194/nhess-19-1541-2019, 2019.

Lionello, P., Nicholls, R. J., Umgiesser, G., and Zanchettin, D.: Venice flooding and sea level: past evolution, present issues, and future projections (introduction to the special issue), Nat. Hazards Earth Syst. Sci., 21, 2633-2641, https://doi.org/10.5194/nhess-21-2633-2021, 2021.

Malačič, V., Viezzoli, D., and Cushman-Roisin, B.: Tidal dynamics in the northern Adriatic Sea, J. Geophys. Res.-Oceans., 105, 26265-26280, 2000. 
Manca, B., Mosetti, F., and Zennaro, P.: Analisi spettrale delle sesse dell'Adriatico, B. Geofis. Teor. Appl., 16, 51-60, 1974.

Marcos, M., Jordà, G., Gomis, D., and Pérez, B.: Changes in storm surges in southern Europe from a regional model under climate change scenarios, Global Planet. Change, 77, 116-128, 2011.

Markowsky, P. and Richardson, Y.: Mesoscale Meteorology in Midlatitudes, Wiley-Blackwell, Chichester, 407 pp., 2010.

Martínez-Asensio, A., Marcos, M., Tsimplis, M. N., Gomis, D., Josey, S., and Jordà, G.: Impact of the atmospheric climate modes on Mediterranean sea level variability, Global Planet. Change, 118, 1-15, 2014.

Martínez-Asensio, A., Tsimplis, M. N., and Calafat, F. M.: Decadal variability of European sea level extremes in relation to the solar activity, Geophys. Res. Lett., 43, 11744-11750, 2016.

Mel, R. and Lionello, P.: Storm surge ensemble prediction for the city of Venice, Weather Forecast., 29, 1044-1057, 2014.

Mel, R., Sterl, A., and Lionello, P.: High resolution climate projection of storm surge at the Venetian coast, Nat. Hazards Earth Syst. Sci., 13, 1135-1142, https://doi.org/10.5194/nhess13-1135-2013, 2013.

Mel, R., Carniello, L., and D'Alpaos, L.: Dataset of wind setup in a regulated Venice lagoon, Data in brief, 26, 104386, https://doi.org/10.1016/j.dib.2019.104386, 2019.

Mentaschi, L., Vousdoukas, M., Voukouvalas, E., Sartini, L., Feyen, L., Besio, G., and Alfieri, L.: The transformed-stationary approach: a generic and simplified methodology for non-stationary extreme value analysis, Hydrol. Earth Syst. Sci., 20, 3527-3547, https://doi.org/10.5194/hess-20-3527-2016, 2016.

Mentaschi, L., Vousdoukas, M. I., Voukouvalas, E., Dosio, A., and Feyen, L.: Global changes of extreme coastal wave energy fluxes triggered by intensified teleconnection patterns, Geophys. Res. Lett., 44, 2416-2426, 2017.

Međugorac, I., Pasarić, M. and Orlić, M. Two recent storm-surge episodes in the Adriatic, Int. J. Saf. Secur. Eng., 6, 589-596, https://doi.org/10.2495/SAFE-V6-N3-589-596 2016.

Međugorac, I., Orlić, M., Janeković, I., Pasarić, Z., and Pasarić, M.: Adriatic storm surges and related cross-basin sea-level slope, J. Mar. Syst., 181, 79-90, 2018.

Neu, U., Akperov, M. G., Bellenbaum, N., Benestad, R., Blender, R., Caballero, R., Cocozza, A., Dacre, H. F., Feng, Y., Fraedrich, K., Grieger, J., Gulev, S., Hanley, J., Hewson, T., Inatsu, M., Keay, K., Kew, S. F., Kindem, I., Leckebusch, G. C., Liberato, M. L. R., Lionello, P., Mokhov, I. I., Pinto, J. G., Raible, C. C., Reale, M., Rudeva, I., Schuster, M., Simmonds, I., Sinclair, M., Sprenger, M., Tilinina, N. D., Trigo, I. F., Ulbrich, S., Ulbrich, U., Wang, X. L., and Wernli, H.: Imilast: A community effort to intercompare extratropical cyclone detection and tracking algorithms, B. Am. Meteorol. Soc., 94, 529-547, 2013.

Nissen, K. M., Leckebusch, G. C., Pinto, J. G., and Ulbrich, U.: Mediterranean cyclones and windstorms in a changing climate, Reg. Environ. Change, 14, 1873-1890, 2014.

NOAA - National Oceanic and Atmospheric Administration Physical Sciences Laboratory (PSL): NCEP/NCAR reanalysis data, [data set], available at: https://psl.noaa.gov/data/gridded/ data.ncep.reanalysis.html, last access: 1 August 2021.

Oppenheimer, M., Glavovic, B., Hinkel, J., Van de Wal, R., Magnan, A. K., Abd-Elgawad, A., Cai, R., Cifuentes-Jara, M., Deconto, R. M., and Ghosh, T.: Sea level rise and implications for low-lying islands, coasts and communities, IPCC Special
Report on the Ocean and Cryosphere in a Changing Climate, edited by: Pörtner, H.-O., Roberts, D. C., Masson-Delmotte, V., Zhai, P., Tignor, M., Poloczanska, E., Mintenbeck,K., Alegría, A., Nicolai, M., Okem, A., Petzold, J., Rama, B., and Weyer, N. M., available at: https://www.ipcc.ch/srocc/chapter/chapter4-sea-level-rise-and-implications-for-low-lying-islands-coastsand-communities/ (last access: 1 August 2021), 2019.

Orlić, M.: On the frictionless influence of planetary atmospheric waves on the Adriatic sea level, J. Phys. Oceanogr., 13, 13011306, 1983.

Orlić, M.: Anatomy of sea level variability-an example from the Adriatic, The Ocean Engineering Handbook, CRC Press, Boca Raton, USA, 2001.

Pasarić, M. and Orlić, M.: Long-term meteorological preconditioning of the North Adriatic coastal floods, Cont. Shelf Res., 21, 263-227, 2001.

Pirazzoli, P. A. and Tomasin, A.: Recent Evolution of Surge-Related Events in the Northern Adriatic Area, J. Coast. Res., 18, 537554, 2001.

Raicich, F.: Long-term variability of storm surge frequency in the Venice Lagoon: an update thanks to 18th century sea level observations, Nat. Hazards Earth Syst. Sci., 15, 527-535, https://doi.org/10.5194/nhess-15-527-2015, 2015.

Reale, M. and Lionello, P.: Synoptic climatology of winter intense precipitation events along the Mediterranean coasts, Nat. Hazards Earth Syst. Sci., 13, 1707-1722, https://doi.org/10.5194/nhess-13-1707-2013, 2013.

Reale, M., Liberato, M. L. R., Lionello, P., Pinto, J. G., Salon, S., and Ulbrich, S.: A global climatology of explosive cyclones using a multi-tracking approach, Tellus A, 71, 1611340, https://doi.org/10.1080/16000870.2019.1611340, 2019.

Reale, M., Cabos, W., Cavicchia, L., Conte, D., Coppola, E., Flaounas, E., Giorgi, F., Hochman, A., Li, L., Lionello, P., Podrascanin, Z., Sanchez Gomez, E., Scoccimarro, E., Sein, D., and Somot, S.: Future projections of Mediterranean cyclone characteristics using the Med-CORDEX ensemble of coupled regional climate system models, Clim. Dynam., in review, 2021.

Robinson, A. R., Tomasin, A., and Artegiani, A.: Flooding Venice phenomenology and prediction of the Adriatic Storm surge, Q. J. Roy. Meteor. Soc., 99, 688-692, 1973.

Roland, A., Cucco, A., Ferrarin, C., Hsu, T.-W., Liau, J.-M., Ou, S.H., Umgiesser, G., and Zanke, U.: On the development and verification of a 2-D coupled wave-current model on unstructured meshes, J. Marine Syst., 78, S244-S254, 2009.

Royal Observatory of Belgium: Sunspot Index and Long-term Solar Observations, available at: https://wwwbis.sidc.be/silso/ datafiles, last access: 1 August 2021.

Rusconi, A.: Il Comune Marino a Venezia: ricerche e ipotesi sulle sue variazioni altimetriche e sui fenomeni naturali che le determinano, Min. Lavori Pubblici, Ufficio Idrografico Magistrato alle Acque, Publ. No. 157, Venice, Italy, 1983.

Sarretta, A., Pillon, S., Molinaroli, E., Guerzoni, S., and Fontolan, G.: Sediment budget in the Lagoon of Venice, Italy, Cont. Shelf Res., 30, 934-949, https://doi.org/10.1016/j.csr.2009.07.002, 2010.

Šepić, J., Vilibić, I., and Belušić, D.: Source of the 2007 Ist meteotsunami (Adriatic Sea), J. Geophys. Res. Oceans., 114, C03016, https://doi.org/10.1029/2008JC005092, 2009. 
Thiéblemont, R., Matthes, K., Omrani, N.-E., Kodera, K., and Hansen, F. : Solar forcing synchronizes decadal North Atlantic climate variability, Nat. Commun., 6, 8268, https://doi.org/10.1038/ncomms9268, 2015.

Tomasin, A.: The frequency of Adriatic surges and solar activity.: Istituto Studio Dinamica Grandi Masse (ISDGM-CNR), ISDGM Tech Rep, 194, 1-8, 2002.

Tomasin, A. and Frassetto, R.: Cyclogenesis and forecast of dramatic water elevations in Venice, Elsevier Oceanography Series, 25, 427-438, Elsevier, 1979.

Toreti, A., Xoplaki, E., Maraun, D., Kuglitsch, F. G., Wanner, H., and Luterbacher, J.: Characterisation of extreme winter precipitation in Mediterranean coastal sites and associated anomalous atmospheric circulation patterns, Nat. Hazards Earth Syst. Sci., 10, 1037-1050, https://doi.org/10.5194/nhess-10-1037-2010, 2010.

Trigo, I. F. and Davies, T. D.: Meteorological conditions associated with sea surges in Venice: a 40 year climatology, Int. J. Climatol., 22, 787-803, 2002.

Trigo, I. F., Davies, T. D., and Bigg, G. R.: Objective climatology of cyclones in the Mediterranean region, J. Climate, 12, 1685-1696, 1999.

Trigo, I. F., Bigg, G. R., and Davies, T. D.: Climatology of Cyclogenesis Mechanisms in the Mediterranean, Mon. Weather Rev., 130, 549-569, 2002.

Troccoli, A., Zambon, F., Hodges, K. I., and Marani, M.: Storm surge frequency reduction in Venice under climate change, Clim. Change, 113, 1065-1079, 2012.

Ulbrich, U., Leckebusch, G. C., and Pinto, J. G.: Extra-tropical cyclones in the present and future climate: a review, Theor. Appl. Climatol., 96, 117-131, 2009.

Ulbrich, U., Lionello, P., Belušić, D., Jacobeit, J., Knippertz, P., Kuglitsch, F. G., Leckebusch, G. C., Luterbacher, J., Maugeri, M., Maheras, P., Nissen, K. M., Pavan, V., Pinto, J. G., Saaroni, H., Seubert, S., Toreti, A., Xoplaki, E., and Ziv, B.: Climate of the mediterranean: Synoptic patterns, temperature, precipitation, winds, and their extremes, The Climate of the Mediterranean Region, https://doi.org/10.1016/B978-0-12416042-2.00005-7, 301-346, 2012.

Ulbrich, U., Leckebusch, G. C., Grieger, J., Schuster, M., Akperov, M., Bardin, M. Y., Feng, Y., Gulev, S., Inatsu, M., Keay, K., Kew, S. F., Liberato, M. L. R., Lionello, P., Mokhov, I. I., Neu, U., Pinto, J. G., Raible, C. C., Reale, M., Rudeva, I., Simmonds, I., Tilinina, N. D., Trigo, I. F., Ulbrich, S., Wang, X. L., and Wernli, H.: Are Greenhouse Gas Signals of Northern Hemisphere winter extra-tropical cyclone activity dependent on the identification and tracking algorithm?, Meteorol. Z., 22, 61-68, 2013.

Umgiesser, G., Canu, D. M., Cucco, A., and Solidoro, C.: A finite element model for the Venice Lagoon. Development, set up, calibration and validation, J. Marine Syst., 51, 123-145, 2004.
Umgiesser, G., Bajo, M., Ferrarin, C., Cucco, A., Lionello, P., Zanchettin, D., Papa, A., Tosoni, A., Ferla, M., Coraci, E., Morucci, S., Crosato, F., Bonometto, A., Valentini, A., Orlić, M., Haigh, I. D., Nielsen, J. W., Bertin, X., Fortunato, A. B., Pérez Gómez, B., Alvarez Fanjul, E., Paradis, D., Jourdan, D., Pasquet, A., Mourre, B., Tintoré, J., and Nicholls, R. J.: The prediction of floods in Venice: methods, models and uncertainty (review article), Nat. Hazards Earth Syst. Sci., 21, 2679-2704, https://doi.org/10.5194/nhess-21-2679-2021, 2021.

Vilibić, I. and Šepić, J.: Destructive meteotsunamis along the eastern Adriatic coast: Overview, Phys. Chem. Earth, Parts A/B/C, 34, 904-917, https://doi.org/10.1016/j.pce.2009.08.004, 2009.

Vousdoukas, M. I., Voukouvalas, E., Annunziato, A., Giardino, A., and Feyen, L.: Projections of extreme storm surge levels along Europe, Clim. Dynam., 47, 3171-3190, 2016.

Vousdoukas, M. I., Mentaschi, L., Voukouvalas, E., Verlaan, M., and Feyen, L.: Extreme sea levels on the rise along Europe's coasts, Earth's Future, 5, 304-323, 2017.

Vousdoukas, M. I., Mentaschi, L., Voukouvalas, E., Verlaan, M., Jevrejeva, S., Jackson, L. P., and Feyen, L.: Global probabilistic projections of extreme sea levels show intensification of coastal flood hazard, Nat. Commun., 9, 2360, https://doi.org/10.1038/s41467-018-04692-w, 2018.

Wilks, D. S.: Statistical methods in the atmospheric sciences, third edition, Academic Press, Oxford, UK, 676 pp., 2011.

Zanchettin, D., Rubino, A., Traverso, P., and Tomasino, M.: Teleconnections force interannual-to-decadal tidal variability in the Lagoon of Venice (northern Adriatic), J. Geophys. Res.-Atmos., 114, D07106, https://doi.org/10.1029/2008JD011485, 2009.

Zanchettin, D., Bruni, S., Raicich, F., Lionello, P., Adloff, F., Androsov, A., Antonioli, F., Artale, V., Carminati, E., Ferrarin, C., Fofonova, V., Nicholls, R. J., Rubinetti, S., Rubino, A., Sannino, G., Spada, G., Thiéblemont, R., Tsimplis, M., Umgiesser, G., Vignudelli, S., Wöppelmann, G., and Zerbini, S.: Sea-level rise in Venice: historic and future trends (review article), Nat. Hazards Earth Syst. Sci., 21, 2643-2678, https://doi.org/10.5194/nhess21-2643-2021, 2021.

Zantedeschi, F.: Intorno alla inondazione accaduta in Venezia nel giorno 15 di gennajo del 1867, Atti r. Ist. Veneto Sc. Lett. Arti, 940-942, 1866-67.

Zappa, G., Shaffrey, L. C., Hodges, K. I., Sansom, P. G., and Stephenson, D. B.: A multimodel assessment of future projections of North Atlantic and European extratropical cyclones in the CMIP5 climate models, J. Climate, 26, 5846-5862, 2013.

Zappa, G., Hawcroft, M. K., Shaffrey, L., Black, E., and Brayshaw, D. J.: Extratropical cyclones and the projected decline of winter Mediterranean precipitation in the CMIP5 models, Clim. Dynam., 45, 1727-1738, 2015. 